\title{
Copper extrusion 3D printing using metal injection moulding feedstock: analysis of process parameters for green density and surface roughness optimization
}

\author{
Gurminder Singh*, Jean-Michel Missiaen, Didier Bouvard and Jean-Marc Chaix \\ Univ. Grenoble Alpes, CNRS, Grenoble INP, SIMAP, 38000 Grenoble, France \\ *Corresponding author email: Gurmindersingh2012@gmail.com
}

\begin{abstract}
In the present study, the extrusion-based 3D printing process was explored using metal injection moulding (MIM) copper feedstock to fabricate dense copper parts. The influence of process parameters of 3D printing, namely layer thickness, nozzle speed, extrusion multiplier and extrusion temperature on green density and surface roughness were studied. Based on the central composite design method, a set of experiments was chosen to study the individual and interaction effects of parameters. Analysis of variance was performed to identify the significant factors and statistical models were obtained by regression analysis. The green density was observed to increase with varying the layer thickness from 0.25 to $0.05 \mathrm{~mm}$ and nozzle speed from 100 to $20 \mathrm{~mm} / \mathrm{s}$. Similarly, surface roughness was improved by decreasing the layer thickness and the nozzle speed and by increasing the extrusion multiplier up to a specific value. The extrusion temperature gave the best results at $200^{\circ} \mathrm{C}$ for both green density and surface roughness. The significant interactions between the parameters for both green density and surface roughness were also studied. A multi-objective optimization approach was used to maximize the green density and minimize the surface roughness within the range of the parameters. Micro-tomography scans were used to analyze the porosity and voids in samples printed with optimized and non-optimized parameters. Besides, sintering was performed on the optimized printed sample to fabricate a dense copper part and analyze linear shrinkage during sintering. Sintered copper parts with high density and low surface roughness were obtained with the optimized printing process parameters.
\end{abstract}

Keywords: Extrusion printing; sintering; copper; green density; response surface methodology; optimization; surface roughness. 


\section{Introduction}

Pure copper is one of the extensively used non-ferrous metals in the modern industry due to outstanding thermal and electrical properties. Also, good structural strength, antimicrobial properties, high corrosion resistance and low cost of copper increase its versatility for different applications in the pure state. Several manufacturing processes like casting, machining and welding have been used for the fabrication of copper components with different shape designs. However, the design-freedom for customized fabrication is limited to these processes. The metalinjection-moulding (MIM) route, including debinding and sintering steps, has also been widely used for the fabrication of copper complex shapes for heat sinks, ornaments, and other applications $[1,2]$. This route results in better surface finish, highly dense structure and allows the manufacture of complex parts. However, the fabrication of a moulding die for every single, or customized design is cumbersome and costly.

In the last decade, metal additive manufacturing (AM) has become common among other conventional processes for the manufacturing of complex metal components [3]. The processes such as selective laser melting (SLM), and laser engineered net shaping (LENS), have been used for different materials such as steels, aluminium, nickel, and titanium alloys [4]. However, the high thermal conductivity of copper challenges laser-based AM techniques to fabricate complex shapes with low porosity [5]. The high thermal conductivity leads to a strong reflection of the thermal energy of the laser or to the transfer of the heat from the melt pool to the previously solidified layer [6-8]. The fabricated parts result in low weight density and poor surface quality [9]. Also, the high reflectivity damages and reduces mirror life in SLM by back laser reflection [10]. Several methods have been investigated to reduce the limitation of reflectivity by alloying copper with tin or zinc to get a denser structure [11-13]. However, the electrical and thermal properties of the alloys have deteriorated relative to pure copper. Electron beam melting (EBM) AM process has made it possible to fabricate dense copper parts due to the non-influence of optical reflectivity of the materials [14]. However, EBM-fabricated specimens exhibit defects like cracks, porosity, shape distortion or internal stresses [15-18]. Also, the cost of these direct AM metal techniques is high due to the equipment price.

Indirect $\mathrm{AM}$ techniques combining $\mathrm{3D}$ printing and pressureless sintering have shown remarkable performance to fabricate pure copper components at low cost $[19,20]$. Bai and 
Williams [21] first reported the use of binder-jet 3D printing combined with pressureless sintering for the fabrication of copper parts. Copper spherical particles were packed layer-by-layer using adhesives deposited by a nozzle as per the CAD (computer-aided design) model. Later, the green part was debinded (removal of adhesives) and sintered at a temperature near the melting point of copper to get a dense copper part. However, a relative density of about $80 \%$ was achieved, even at the highest sintering temperature of $1080^{\circ} \mathrm{C}$. Different particles sizes, along with different sintering parameters, were explored to get better-sintered samples [22]. Moreover, the authors reported the use of hot isostatic pressing as a post-processing step to acquire high relative density $~ 97 \%$ from $90 \%$ sintered density using mixed particle sizes. Singh and Pandey [23-25] reported a novel process of fabricating pure copper complex shapes using polymer 3D printing and ultrasonicassisted copper powder filling and sintering. The process has shown the ability to fabricate copper complex parts, including overhanging and graded structures [26]. However, the process resulted in low relative density ( $\sim 4 \%$ ) with a surface finish larger than $\sim 20 \mu \mathrm{m}$ without post-processing. Also, the process was limited to large dimensions, and it needed a long post-processing step to remove investment powder from the mould to get dense copper parts [27].

Several researchers have also explored the combination of extrusion 3D printing and sintering in the last few years for the fabrication of different metals and ceramics [28-32]. Hong et al. [33] reported the fabrication of copper parts by extrusion of copper-binder composite paste, followed by debinding and pressureless sintering. The paste was optimized with $82 \mathrm{wt} \%$ copper to ensure good adhesion between the layers during 3D printing. The fill density and nozzle printing speed effects were studied for suitable printing. A linear shrinkage of 23\% was obtained after sintering the green part at $950^{\circ} \mathrm{C}$ for $2 \mathrm{~h}$, but a significant porosity remained. Also, the fabricated green and sintered samples resulted in low surface finish. Yan et al. [34] reported the fabrication of copper 3D samples using extrusion 3D printing and sintering. Copper particles of $0.5 \mu \mathrm{m}$ size were mixed with binders to obtain a paste for the printing. The printing parameters, such as layer height, retraction distance and extrusion amount, were studied to obtain suitable green parts. A relative density of $\sim 87 \%$ along with $\sim 15 \%$ linear shrinkage and $\sim 9 \%$ mass reduction was reported after sintering at $1050{ }^{\circ} \mathrm{C}$. Zhao et al. [35] also proved the feasibility of extrusion printing, followed by sintering to obtain dense copper parts. However, the authors have not given any information on the microstructure and mechanical properties of their 3D printed parts. Ren et al. [36] also reported the copper free form fabrication by extrusion 3D printing and sintering. Copper particles 
of 200 -mesh size mixed with a binder were extruded at $160{ }^{\circ} \mathrm{C}$ layer-by-layer for the fabrication of the green part. The effect of raster angle, layer thickness and infill degree were studied by the design of experiments to obtain maximum tensile strength of the green part. Besides, printed green samples were sintered at high temperature $\left(1083^{\circ} \mathrm{C}\right)$ to obtain $\sim 90 \%$ relative density. However, a high dimensional shrinkage of more than $20 \%$ was observed during sintering and final materials had a bad surface finish and contained many impurities.

It is clear from the literature that extrusion-based 3D printing followed by sintering is a promising route to fabricate highly dense copper parts. However, no extensive work has been performed to study the effect and optimization of printing parameters to obtain samples with high green density of copper, by minimizing internal printing voids, which could lead to final sintered parts with high relative density. Only, Godec et al. [30] have performed an optimization study for the tensile properties of 17-4PH stainless steel green body processed by fused filament deposition. Also, no work has been performed to optimize the surface finish. Finally, the raw materials used in the literature need to be prepared specially for the 3D printing process, which is cumbersome for the production work. In the present work, market available metal injection moulding (MIM) copper feedstock was directly used for the copper-composite 3D printing with a 3D extrusion printing machine from AIM3D, Germany. The ability to print hard-metal and cermet component with complex shapes and possibly internal cooling channels by AIM3D printer has already been shown in the literature [37]. Therefore, a comprehensive study of 3D printing parameters to obtain maximum green density and minimum surface roughness was performed to avoid printing voids for copper material. The effects of layer thickness, nozzle moving speed, extrusion temperature and extrusion multiplier (flow rate) on the green density and surface finish were studied. The statistical approach using design of experiment (DOE) and analysis of variance (ANOVA) was used to obtain regression models. Besides, optimization of parameters was carried out to maximize the green density and minimize the surface roughness of the printed parts. A micro-tomography analysis was performed on the printed samples with optimized and non-optimized parameters to visualize the voids resulting from printing. Finally, the sample printed with optimized parameters was sintered to obtain a dense copper part.

\section{Materials and methods}

\subsection{Feedstock material}


A commercially available copper MIM feedstock with $93.5 \mathrm{wt} \%$ of copper (polyMIM Cu999 from PolyMIM, Germany) was used directly for the extrusion 3D printing. The SEM image ofcopper particles of a feedstock granule after debinding is shown in Fig. 1 (a). The average particle size of the copper particles was $5.9 \mu \mathrm{m}$, and the particle size distribution is shown in Fig. 1 (b). The feedstock contains Polyethylene glycol (PEG) and wax as binders. PEG is a thermoplastic that provides the required viscosity for hot extrusion during printing. Also, this binder is environmentally friendly and water-soluble. The second binder wax acts as the backbone binder, which remains after the first debinding step to hold the copper particles together before sintering starts. TGA (Thermogravimetric analysis) curve of the feedstock with $1^{\circ} \mathrm{C} / \mathrm{min}$ heating rate up to $500^{\circ} \mathrm{C}$ temperature in $\mathrm{He}-4 \% \mathrm{H}_{2}$ gas mixture is shown in Fig. 1 (c). The weight loss starts around $180{ }^{\circ} \mathrm{C}$ and the total weight loss is $6.45 \%$, with a maximum weight loss rate between 300 and 350 ${ }^{\circ} \mathrm{C}$. The two weight loss steps observed between 300 and $450^{\circ} \mathrm{C}$ probably correspond to the disappearance of the two different polymers, PEG and wax. 
(a)
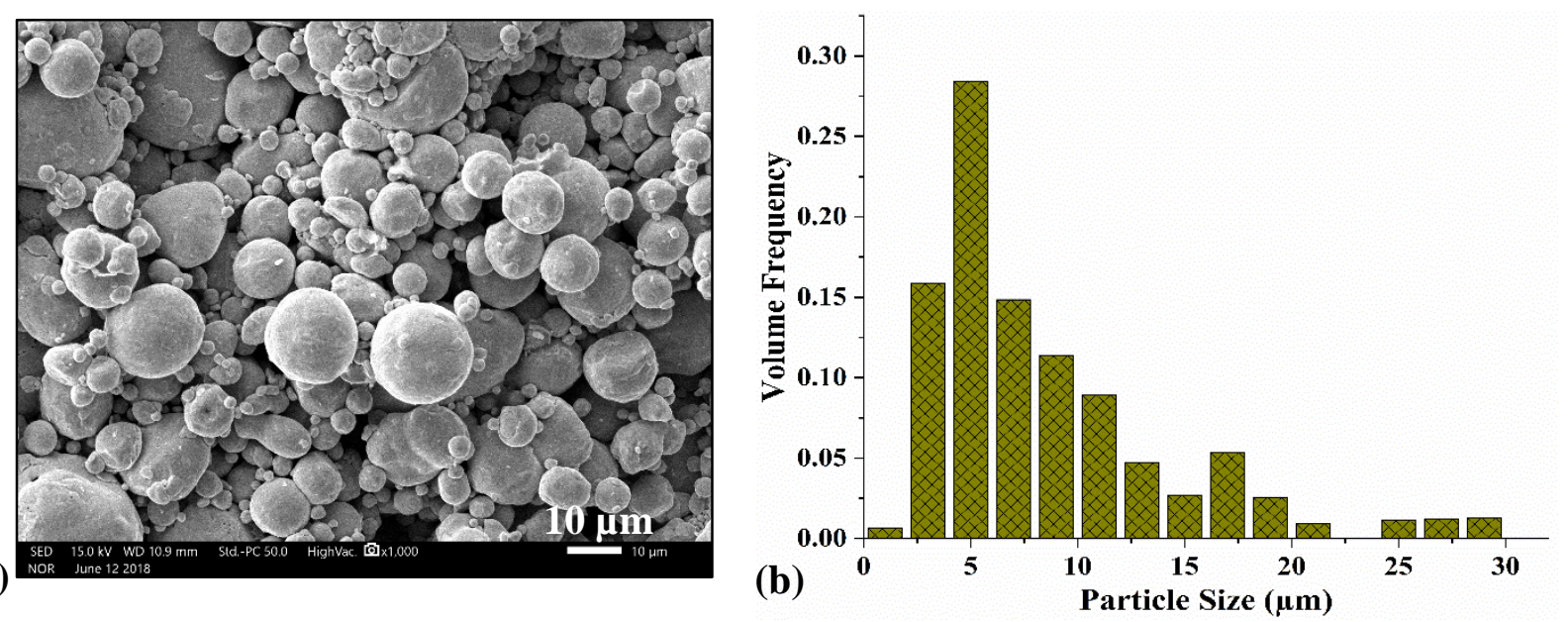

(c)

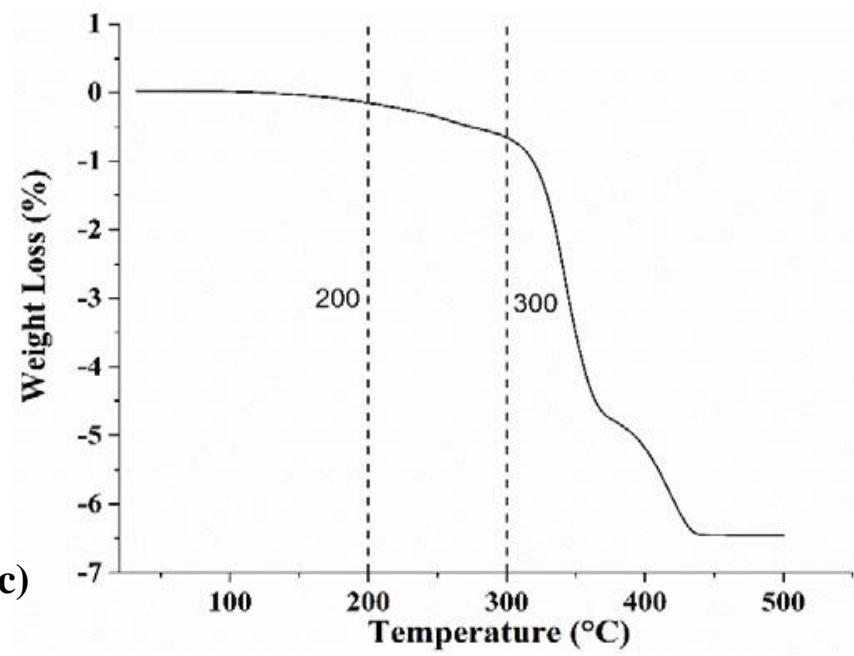

Fig. 1: (a) SEM image of copper particles of a feedstock granule, (b) particle size distribution and (c) TGA curve of feedstock at $1^{\circ} \mathrm{C} / \mathrm{min}$ heating rate. 


\section{$2.23 D$ printing}

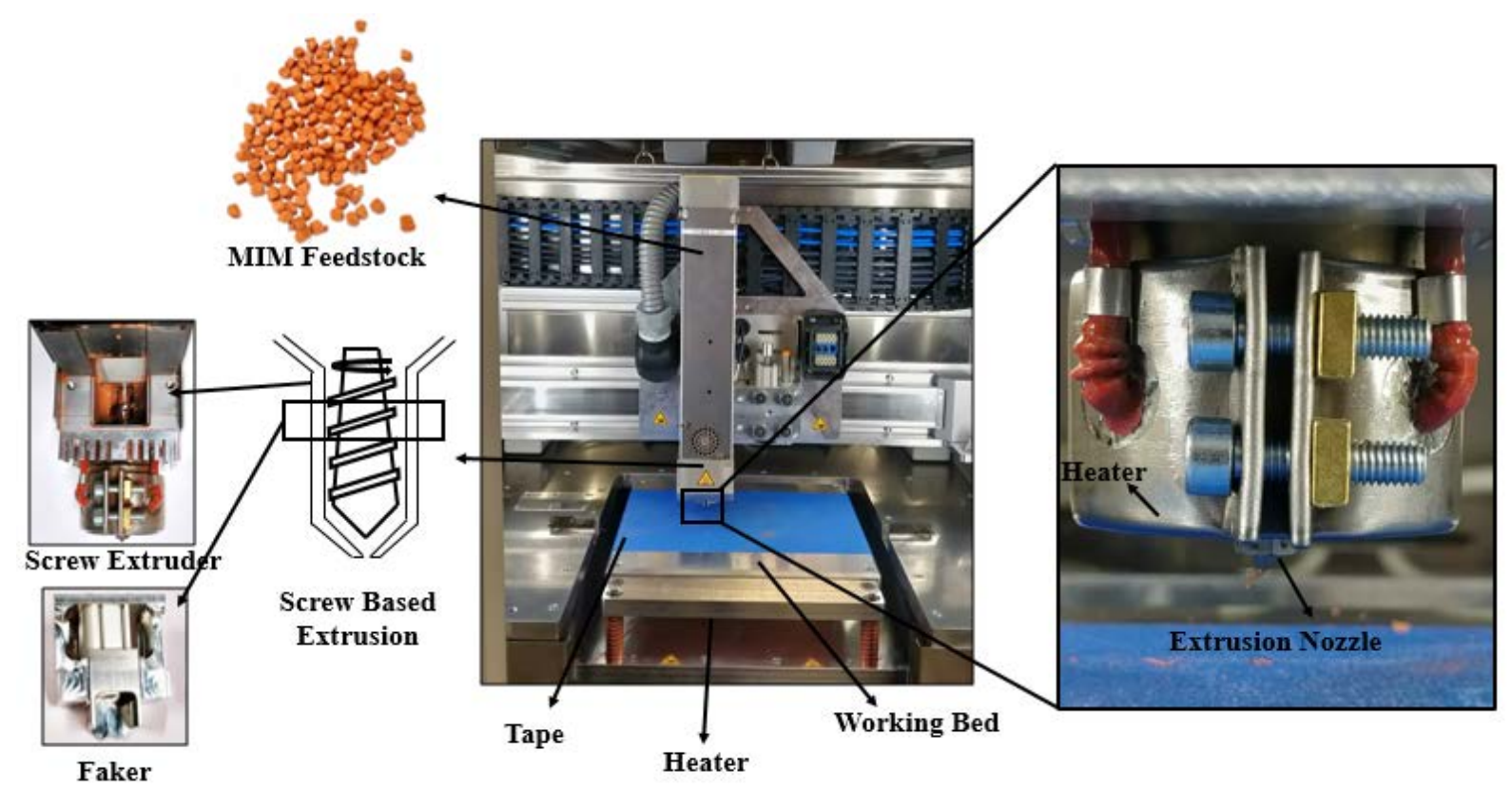

Fig. 2: Details of MIM feedstock screw-based extrusion 3D printer.

An ExAM 255 screw-based extrusion 3D printer from AIM3D (Germany) was used for the printing process. Details of the printing device are shown in Fig. 2. The build space for printing was $255 \times 255 \times 255 \mathrm{~mm}$ with repeatability of $10 \mu \mathrm{m}$ in the z-axis and $50 \mu \mathrm{m}$ in $\mathrm{x}$ and $\mathrm{y}$ axes. The feedstock was supplied from the hopper, and a faker (pneumatic power piston) was used to flow the feedstock continuously to the extruder. The screw-based extruder extruded the material from a $0.4 \mathrm{~mm}$ diameter nozzle made of hardened steel at a controlled temperature, called extrusion temperature. The CAD drawing of the desired shape of the sample was modelled and tessellated in SolidWorks (USA) software. The slicing procedure was performed in Simplify3D (USA) software and stored as a g-code file for communication with the printer. The infill density for the printing process was kept constant at $100 \%$ for all experiments. Also, the rectilinear infill pattern with $\pm 45^{\circ}$ offset in each layer was selected.

The specimens fabricated for the study of printing parameter optimization were 8-mm edge cubes. These cubes were large enough to allow precise mass, volume and surface roughness measurement and small enough to be introduced in the sintering dilatometer. Additional cylindrical specimens were printed for the tomography analysis with $8 \mathrm{~mm}$ diameter and height. For better 
adhesion to the printing bed, 3M adhesive blue tape was placed on the bed and the nozzle speed for the first layer was set at $50 \%$ of the actual nozzle speed. After preliminary observations, the operating bed temperature was held at $60^{\circ} \mathrm{C}$ during printing. Digital microscope images of samples fabricated with $0.2 \mathrm{~mm}$ layer thickness at different bed temperatures are shown in Fig. 3. A wrapping defect on the first printed layer was observed with $50^{\circ} \mathrm{C}$ bed temperature. A few initial layers were found to collapse as the bed temperature was increased from 70 to $90^{\circ} \mathrm{C}$. The part fabricated with $60^{\circ} \mathrm{C}$ bed temperature resulted in better adhesion to the working bed. This behavior is probably related to the melting of the PEG polymer which usually starts around $60-70^{\circ} \mathrm{C}$. Four significant parameters, layer thickness, nozzle speed, extrusion multiplier (flow rate) and extrusion temperature were varied to study their effect on the printing performance by the design of experiments method. The 3D printing process parameters were optimized using a multi-objective genetic algorithm to obtain maximum green density and minimal surface roughness.
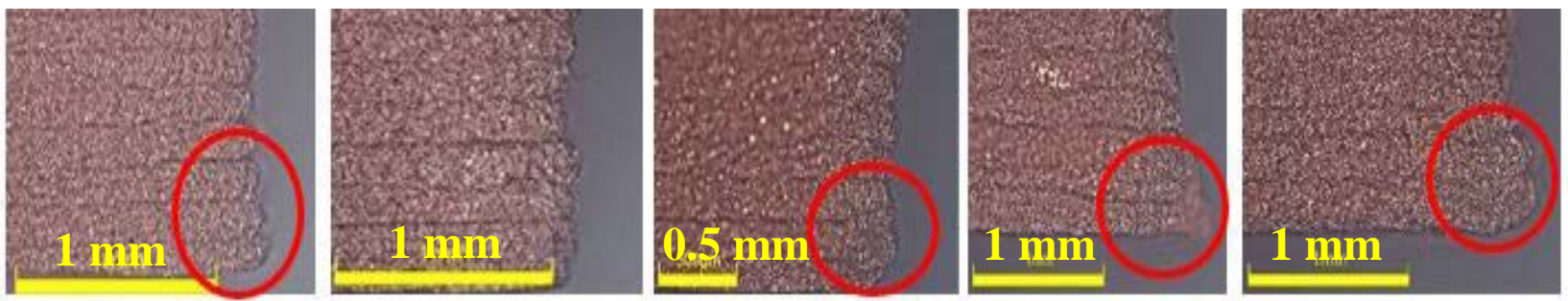

Fig. 3: Microscope images of the samples fabricated at 50, 60, 70, 80 and $90{ }^{\circ} \mathrm{C}$ bed temperature with $0.2 \mathrm{~mm}$ layer thickness.

\subsection{Debinding and sintering}

The sample printed with optimal parameters was debinded in two steps to remove both PEG and wax. First, it was immersed in water for $14 \mathrm{~h}$ to remove PEG (solvent debinding). The solventdebinded sample was then placed in an oven for $2 \mathrm{~h}$ at $100^{\circ} \mathrm{C}$ for drying. Second, thermal debinding was performed, followed by sintering of the sample in a SETARAM (France) vertical dilatometer with $\mathrm{He}-4 \% \mathrm{H}_{2}$ gas flow. The sample was heated at $1{ }^{\circ} \mathrm{C} / \mathrm{min}$ rate up to $500{ }^{\circ} \mathrm{C}$ and kept at this temperature during $1 \mathrm{~h}$ to remove the remaining binders. Then, the sample was sintered with the following thermal cycle: $4^{\circ} \mathrm{C} / \mathrm{min}$ heating up to $950{ }^{\circ} \mathrm{C}$, 3h holding, $4{ }^{\circ} \mathrm{C} / \mathrm{min}$ heating up to 1030 ${ }^{\circ} \mathrm{C}$, 3h holding, $6{ }^{\circ} \mathrm{C} / \mathrm{min}$ cooling. The two-stage sintering cycle was chosen as per the literature [38] to achieve high sintered density.

\subsection{Characterization}


The green weight density (GD) of the 3D printed samples was calculated by measuring their mass and volume. The mass was measured with an accuracy of $0.001 \mathrm{~g}$, and the volume was deduced from the dimensions measured using a Vernier calliper. The measurements were taken three-time to check the repeatability, and the average was calculated. The surface roughness (SR) of the samples in the printing direction was measured using an Olympus DSX500 optical microscope (Japan) as per the ISO 4287 standard. Images of $5 \mathrm{~mm}$ in the printing direction by $3 \mathrm{~mm}$ in the perpendicular direction were taken by mapping. The data were captured in three different locations to ensure repeatability. 3D surface profiles were also taken along the printing direction to observe the 3D view of the surface. Scanning electron microscope (SEM) images were taken by JEOL JSM-IT 500 HR (Japan) with 100x magnification. EDX analysis of the fabricated samples was performed with Bruker EDS at $15 \mathrm{KeV}$. The density of the sintered specimens was determined using the Archimedes' method. A computed microtomography machine (Easytom XL, France) with a laboratory X-ray source was used for the 3D scanning of the samples. The energy of 150 $\mathrm{kV}$ with a voxel size of $5.9 \mu \mathrm{m}$ (or $0.93 \mu \mathrm{m}$ for a final high-resolution image) was used for the scan. 1440 projections were acquired by rotating the sample $360^{\circ}$ around the vertical axis, and full reconstruction of the volume was performed with X-Act software (France) using a classical backprojection algorithm. ImageJ software was used to analyze the tomography data.

\subsection{Design of experiment}

The central composite design (CCD) based response surface methodology (RSM) was used to quantify the effect of process parameters on green density and surface roughness. Such statistical approach helps to analyze the individual and interaction effects of parameters on responses with a small number of experiments and at a low computational cost. Different authors have adopted this methodology in various research fields [39,40]. However, this approach has some limitations. It provides a statistical equation describing parameters interaction, and an estimation the accuracy of approximation. The validation of this equation with experimental results is thus still required. Also, the response surface is not valid for regions outside of the ranges of factor studied. Therefore, the choice of these ranges should be relevant. The statistical analyses were performed with the Minitab (USA) software. The parameter (layer thickness, nozzle speed, extrusion multiplier and extrusion temperature) ranges for the CCD were selected as per the preliminary experiments and machine capability. The levels of these parameters are shown in Table 1. 
The set of 31 experiments based on the CCD approach with actual experimental points are shown in Table 2. The quadratic response surface models for the different responses can be obtained by CCD and ANOVA analysis to enumerate the relation between the input parameter vector $\boldsymbol{X}=\left(X_{1}, X_{2}, \ldots \ldots \ldots, X_{k}\right)^{T}$ and response outputs $Y(\boldsymbol{X})$ as given in Eq. 1.

$$
Y(\boldsymbol{X})=\alpha_{0}+\sum_{i=1}^{k} \alpha_{i} X_{i}+\sum_{i=1}^{k} \alpha_{i i} X_{i}^{2}+\sum_{i<j}^{k} \alpha_{i j} X_{i} X_{j}+\varepsilon,
$$

where $K$ is the number of parameters, $\alpha_{0}, \alpha_{i}, \alpha_{i i}$ and $\alpha_{i j}$ are the parameter-depending constants with $\varepsilon$ a random error and $X_{i}, X_{i}^{2}$ and $X_{i} X_{j}$ are the first order, second order and the interaction terms for the process parameters, respectively. For the present study, $K=4$ for the two different responses $\left(Y=(G D, S R)^{T}\right)$.

Table 1: Parameter level for CCD

\begin{tabular}{|c|c|c|c|c|c|c|c|}
\hline Sr. No. & Names & Parameters / Levels & $\mathbf{- 2}$ & $\mathbf{- 1}$ & $\mathbf{0}$ & $\mathbf{+ 1}$ & $\mathbf{+ 2}$ \\
\hline 1 & $X_{1}$ & Layer Thickness (mm) & 0.05 & 0.1 & 0.15 & 0.2 & 0.25 \\
\hline 2 & $X_{2}$ & Nozzle speed (mm/s) & 20 & 40 & 60 & 80 & 100 \\
\hline 3 & $X_{3}$ & Extrusion Multiplier (\%) & 90 & 105 & 120 & 135 & 150 \\
\hline 4 & $X_{4}$ & Extrusion Temperature $\left({ }^{\circ} \mathrm{C}\right)$ & 180 & 190 & 200 & 210 & 220 \\
\hline
\end{tabular}

Due to experimental errors and non-ideal conditions, statistical variations are observed in practice. By assuming a value $1-\alpha=95 \%$ for the confidence level, the statistical range for the experimental values can be written as

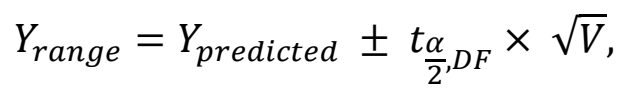

where, $Y_{\text {range }}$ is the range for individual responses, $Y_{\text {predicted }}$ is the predicted value from the

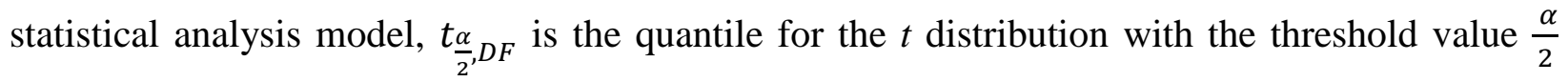
along with (DF) degree of freedom of error and $V$ is the variance error for the response models, respectively. 
Table 2: Actual input factors for the 3D printing and responses

\begin{tabular}{|c|c|c|c|c|c|c|}
\hline $\begin{array}{c}\text { Run } \\
\text { Order }\end{array}$ & $\begin{array}{c}\text { Layer } \\
\text { Thickness } \\
(\mu \mathrm{m})\end{array}$ & $\begin{array}{l}\text { Nozzle } \\
\text { Speed } \\
(\mathrm{mm} / \mathrm{s})\end{array}$ & $\begin{array}{c}\text { Extrusion } \\
\text { Multiplier } \\
\text { (\%) }\end{array}$ & $\begin{array}{c}\text { Extrusion } \\
\text { Temp } \\
\left({ }^{\circ} \mathrm{C}\right)\end{array}$ & $\begin{array}{c}\text { Green Density } \\
\left(\mathrm{g} / \mathrm{cm}^{3}\right)\end{array}$ & $\begin{array}{c}\text { Surface } \\
\text { Roughness } \\
(\mu \mathrm{m})\end{array}$ \\
\hline 1 & 0.05 & 60 & 120 & 200 & 5.03 & 8.214 \\
\hline 2 & 0.15 & 60 & 120 & 200 & 4.78 & 10.856 \\
\hline 3 & 0.1 & 80 & 135 & 190 & 4.80 & 10.356 \\
\hline 4 & 0.15 & 20 & 120 & 200 & 5.20 & 9.876 \\
\hline 5 & 0.2 & 80 & 105 & 210 & 4.03 & 16.845 \\
\hline 6 & 0.15 & 60 & 120 & 200 & 4.69 & 10.558 \\
\hline 7 & 0.2 & 40 & 135 & 210 & 4.80 & 12.902 \\
\hline 8 & 0.2 & 80 & 105 & 190 & 4.10 & 16.856 \\
\hline 9 & 0.15 & 60 & 120 & 200 & 4.68 & 10.169 \\
\hline 10 & 0.1 & 40 & 105 & 190 & 5.08 & 7.870 \\
\hline 11 & 0.15 & 100 & 120 & 200 & 4.32 & 16.234 \\
\hline 12 & 0.2 & 40 & 105 & 210 & 4.46 & 16.845 \\
\hline 13 & 0.1 & 40 & 135 & 190 & 5.10 & 7.025 \\
\hline 14 & 0.15 & 60 & 120 & 200 & 4.71 & 9.756 \\
\hline 15 & 0.2 & 80 & 135 & 190 & 4.70 & 15.125 \\
\hline 16 & 0.25 & 60 & 120 & 200 & 4.49 & 18.146 \\
\hline 17 & 0.15 & 60 & 120 & 220 & 4.28 & 15.181 \\
\hline 18 & 0.1 & 80 & 135 & 210 & 4.64 & 10.856 \\
\hline 19 & 0.2 & 40 & 105 & 190 & 4.76 & 14.085 \\
\hline 20 & 0.1 & 80 & 105 & 210 & 4.29 & 16.539 \\
\hline 21 & 0.15 & 60 & 120 & 200 & 4.74 & 9.985 \\
\hline 22 & 0.2 & 40 & 135 & 190 & 4.97 & 14.863 \\
\hline 23 & 0.15 & 60 & 120 & 200 & 4.75 & 9.756 \\
\hline 24 & 0.15 & 60 & 90 & 200 & 4.30 & 16.09 \\
\hline 25 & 0.1 & 80 & 105 & 190 & 4.46 & 13.982 \\
\hline
\end{tabular}




\begin{tabular}{|l|c|c|c|c|c|c|}
\hline 26 & 0.2 & 80 & 135 & 210 & 4.47 & 14.365 \\
\hline 27 & 0.15 & 60 & 120 & 180 & 4.51 & 13.576 \\
\hline 28 & 0.15 & 60 & 150 & 200 & 5.06 & 11.598 \\
\hline 29 & 0.15 & 60 & 120 & 200 & 4.69 & 11.442 \\
\hline 30 & 0.1 & 40 & 135 & 210 & 4.90 & 6.720 \\
\hline 31 & 0.1 & 40 & 105 & 210 & 4.82 & 10.322 \\
\hline
\end{tabular}

\section{Results and discussion}

\subsection{Experimental runs and statistical analysis}

(a)

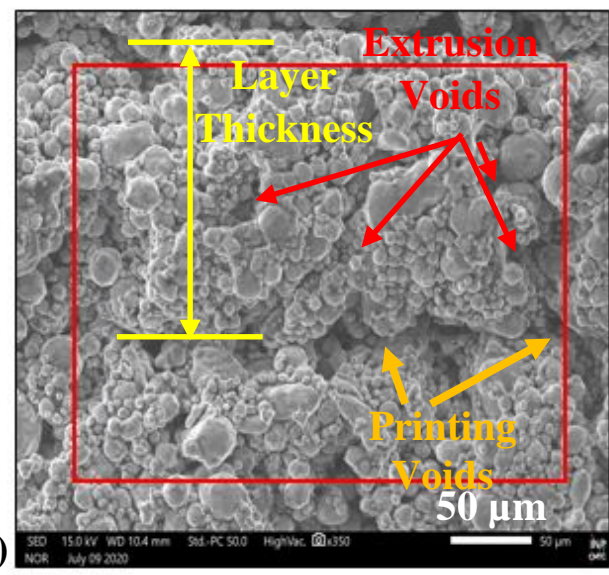

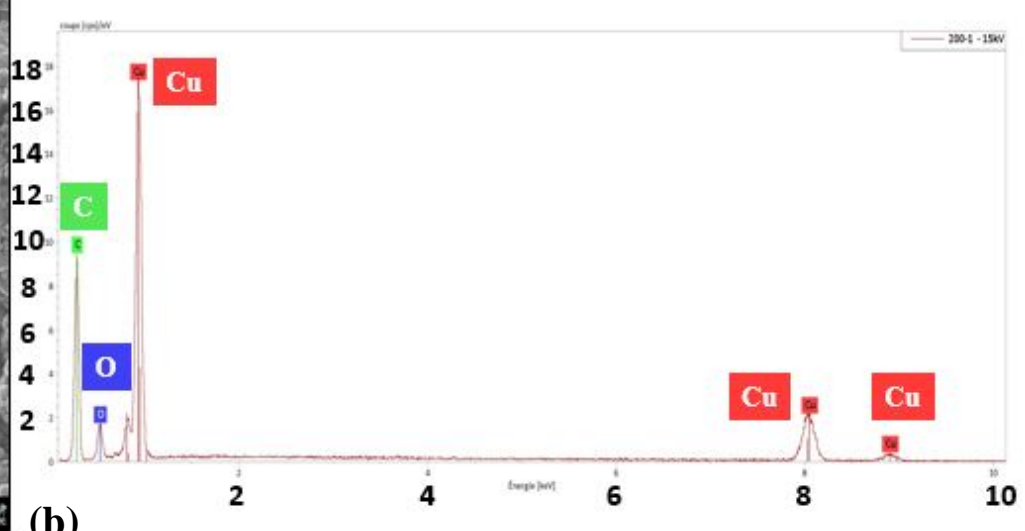

Fig. 4: (a) SEM image of a side of a printed sample and (b) EDX analysis of the printed sample.

The set of 31 samples was printed as per CCD design. The corner point experiments were repeated for higher accuracy. The SEM image of the side of a printed sample is shown in Fig. 4 (a). Two kinds of voids are found and referred to, respectively, as extrusion voids and printing voids. During extrusion, the feedstock material faced numerous types of stresses via faker, screw-extruder and printing parameters, which could damage the material. The resulting voids inside the feedstock material were named 'extrusion voids'. Such voids in the feedstock strands have been marked as extrusion voids in Figure 4a, although it cannot be excluded that some of them are due to surface defects. The second voids were located between the printed filaments and named 'printing voids'. These two types of voids were affected by the printing parameters, as discussed in the next 
subsections. The voids amount should be minimized to get higher green weight density. The EDX analysis of the fabricated sample is shown in Fig. 4. The analysis shows a significant amount of copper and a smaller amount of carbon and oxygen from the binders. The samples were free from any contamination.

The output responses, green density and surface roughness, for all printed samples are given in Table 2. The analysis of variance (ANOVA) was performed on these responses. The insignificant terms with a $p$-value higher than 0.05 were removed from the analysis. Tables $\mathrm{S} 1$ and S2 depicts the ANOVA table for green density and surface roughness with the inclusion of significant terms. The R-square and F value details are also given in the ANOVA tables. The Fvalues describes the adequacy of the models. The regression analysis was performed to obtain the quadratic models for predicting green density (GD) and surface roughness (SR) :

$$
\begin{gathered}
G D=-23.84-10.46 \times X_{1}-0.03786 \times X_{2}-0.01278 \times X_{3}+0.3196 \times X_{4}-0.000820 \\
\quad \times X_{4} \times X_{4}+0.0670 \times X_{1} \times X_{3}+0.000226 \times X_{2} \times X_{3} \\
\quad \begin{array}{rl}
S R=2 & 98.4+36.5 \times X_{1}+0.0568 \times X_{2}-0.019 \times X_{3}-2.957 \times X_{4}+230.8 \times X_{1} \times X_{1} \\
+ & 0.001365 \times X_{2} \times X_{2}+0.003302 \times X_{3} \times X_{3}+0.00877 \times X_{4} \times X_{4}-0.956 \\
& \times X_{1} \times X_{2}-0.00428 \times X_{3} \times X_{4}
\end{array}
\end{gathered}
$$

Here, $X_{1}$ is layer thickness, $X_{2}$ is nozzle speed, $X_{3}$ is extrusion multiplier and $X_{4}$ is extrusion temperature. The statistical error range or standard deviation of the models was calculated at a 95\% confidence level as per Eq. 2 and presented in Eqs. 5 and 6, for green density and surface roughness, respectively. Some experiments were performed outside the CCD parameter combination for validation of the error ranges. The results were observed to be within the statistical error range of the models :

$$
\begin{gathered}
G D_{\text {range }}=G D_{\text {predicted }} \pm 0.11 \\
S R_{\text {range }}=S R_{\text {predicted }} \pm 1.92
\end{gathered}
$$

\subsection{Effect of parameters on green density}

The individual effects of the parameters on the green density are shown in Fig. 5(a). The percentage contribution of the individual terms and their interactions is also given in Fig. 5(b). The nozzle speed and extrusion multiplier are the most dominating parameters. For the set of experiments 
carried out, the green density was in the range 4.1-5.2 $\mathrm{g} / \mathrm{cm}^{3}$. An in-depth discussion about the effect of the parameters on the green density is provided below.

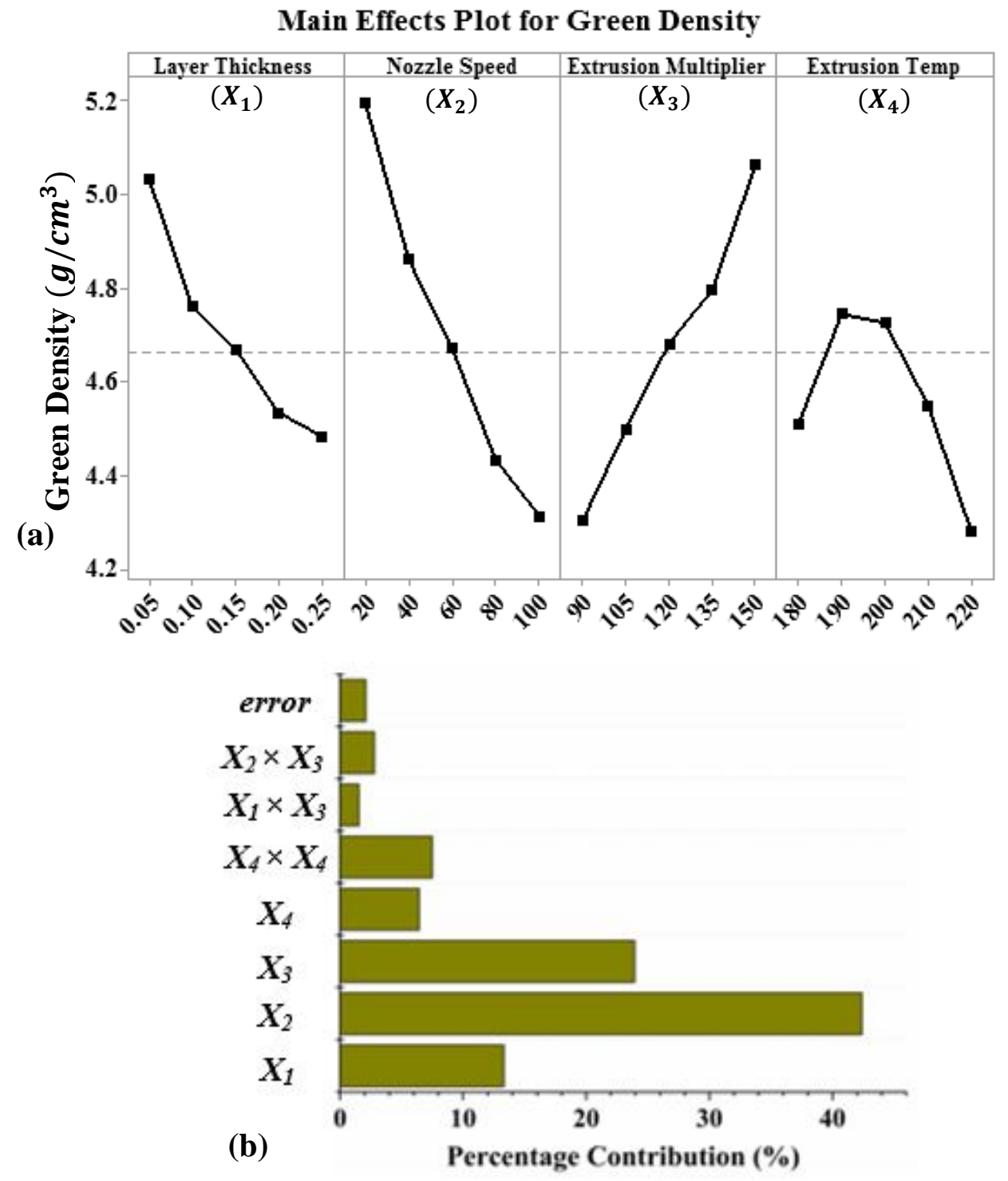

Fig. 5: (a) Parameter effect and (b) percentage contribution for green density.

\subsubsection{Effect of layer thickness}

Layer thickness is the distance between the two printed layers. With increasing layer thickness, the green density is reduced. A smaller layer thickness could reduce the size of the printing voids between the layers and induce shrinkage of the extrusion voids due to the pressure applied for the lateral spreading of material during printing. SEM images were also taken on the surface of the 
samples printed with small and large layer thickness. Large extrusion and printing voids between the layers are observed on the surface of a sample printed with $0.25 \mathrm{~mm}$ layer thickness (Fig. 6 (c)) as compared to the printed sample with $0.15 \mathrm{~mm}$ layer thickness (Fig. 6(b)). The sample printed with a small layer thickness of $0.05 \mathrm{~mm}$ possessed small extrusion and printing voids on the surface (Fig. 6 (a)). Mishra and Pandey [41] also reported the effect of layer thickness on the density of the 3D solvent cast printed iron composite samples. Larger layer thickness resulted in larger voids and lower density. Similarly, Galati and Minetola [42] reported a low residual porosity with $0.05 \mathrm{~mm}$ layer thickness as compared to $0.125 \mathrm{~mm}$ layer thickness with samples of 17-4 PH and binder composite.

\subsubsection{Effect of nozzle speed}

The speed of nozzle movement during material extrusion affects the extruded material morphology significantly. The nozzle speed dominates other parameters for the green density response (Fig. 5(b)). The green density is reduced with the nozzle speed increasing from 20 to $100 \mathrm{~mm} / \mathrm{s}$ (Fig. 5(a)). Slow nozzle speed allows to extrude homogeneous filaments with minimum extrusion voids and also to fill printing voids during material deposition, leading to a higher green density. It is worth notifying here that the material contains a high percentage of copper metal particles. The materials generally used in extrusion-based 3D printing are thermoplastic with ductile properties [43]. However, with high metal particle filling, the composite paste gets more brittle, and a fast nozzle speed could fracture it during extrusion, resulting in large extrusion voids. The SEM images of the samples fabricated with $20 \mathrm{~mm} / \mathrm{s}$ nozzle speed depict a smaller number of extrusion and printing voids as compared to the samples fabricated with $100 \mathrm{~mm} / \mathrm{s}$ nozzle speed (Figs. 6 (d) and (e)). The voids are then observed to increase with increasing nozzle speed, resulting in lower green density. 

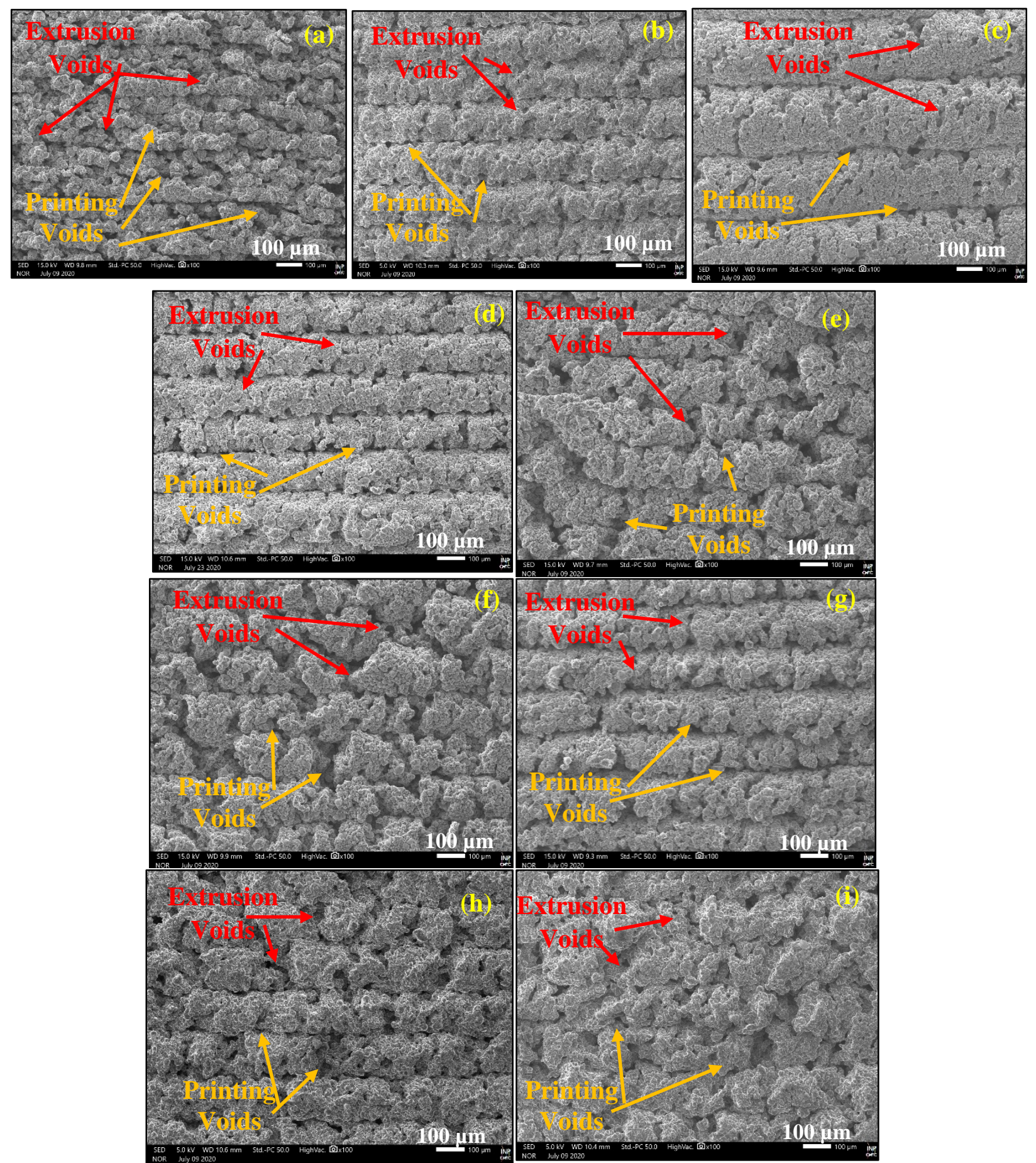

Fig. 6: SEM images of the samples fabricated with varying layer thickness $0.05,0.15$ and 0.25 mm (a-c), nozzle speed 20 and 100 mm/s (d-e), extrusion multiplier 90 and 150 \% (f-g) and extrusion temperature 180 and $220^{\circ} \mathrm{C}$ (h-i). Note: Figs. 6 (a), (c-i) were taken for the samples 
fabricated at the corner points of each parameter and Fig. 6 (b) presents the SEM image of the sample fabricated at the central point.

\subsubsection{Effect of the extrusion multiplier}

The extrusion multiplier is related to the flow rate of the extruded material. $100 \%$ extrusion multiplier corresponds to the standard flow rate. Extrusion multiplier was found to be the secondmost effecting parameter on the green density. As the extrusion multiplier is increased, the green density is observed to increase. A large value of the extrusion multiplier increases the flow rate, that is the amount of deposited material, resulting in smaller extrusion and printing voids and better adhesion with the perimeter layer. The high flow rate resulted in low porosity to give better green density. This behaviour is also noticed in the SEM analysis. Figure 6 (f) depicts the SEM image of the sample fabricated with $90 \%$ extrusion multiplier. Large size printing and extrusion voids are observed, corresponding to a low green density. Also, the nozzle deposited non-homogenous material due to the low flow rate, which decreased the density. With the high extrusion multiplier value of $150 \%$, the deposited material is better connected to the previous layer by overlapping, resulting in smaller extrusion and printing voids. A denser structure of the layers is noticed during SEM analysis of this sample (Fig. 6 (g)). Godec et al. [30] also reported the increment in weight density with increasing the flow rate for the fused filament fabrication of 17-4 PH stainless steel and binder composite.

\subsubsection{Effect of extrusion temperature}

The green density of the samples is increased with the extrusion temperature increasing from 180 to $190^{\circ} \mathrm{C}$. This is probably due to the decrease of viscosity of the material, which made it more deformable. The SEM image of the sample printed at $180^{\circ} \mathrm{C}$ (Fig. 6(f)) depicts a large number of extrusion and printing voids as compared to the sample printed at $200^{\circ} \mathrm{C}$ extrusion temperature (Fig. 6(b)). It also depicts the lack of deposited material and large voids. The samples fabricated at 190 and $200^{\circ} \mathrm{C}$ extrusion temperature have about the same green density. However, this density decreases when the temperature is higher, 210 and $220^{\circ} \mathrm{C}$. This may result from degradation of the binder at such high temperatures. A large number of extrusion voids is then observed on the printed samples (Fig. 6 (g)). TGA curve in Fig. 1 (c) shows that binder removal is more intense above 
$200^{\circ} \mathrm{C}$. However, the TGA experiment was performed in $\mathrm{He}-4 \% \mathrm{H}_{2}$ gas mixture, whereas printing was achieved in air and oxidation may accelerate binder degradation. Hwang et al. [44] reported the effect of extrusion temperature on the tensile strength of the acrylonitrile butadiene styrene (ABS) and copper composite fabricated by fused deposition modelling (FDM) process. The maximum tensile strength was reported at $220{ }^{\circ} \mathrm{C}$ due to better adhesion between the layers and lower viscosity. However, in this study, only $50 \mathrm{wt} \%$ copper was used to fabricate the ABS-Cu composite. The MIM feedstock used in the present work contained $93.5 \mathrm{wt} \%$ of copper. This high percentage of copper particles resulted in large extrusion voids due to the degradation of the binders, and not high enough viscosity at high extrusion temperature. This resulted in a low green density of the sample. Therefore, the sample fabricated at $190^{\circ} \mathrm{C}$ extrusion temperature has the best green density owing to less extrusion and printing voids.

\subsubsection{Effect of interactions}

(a)
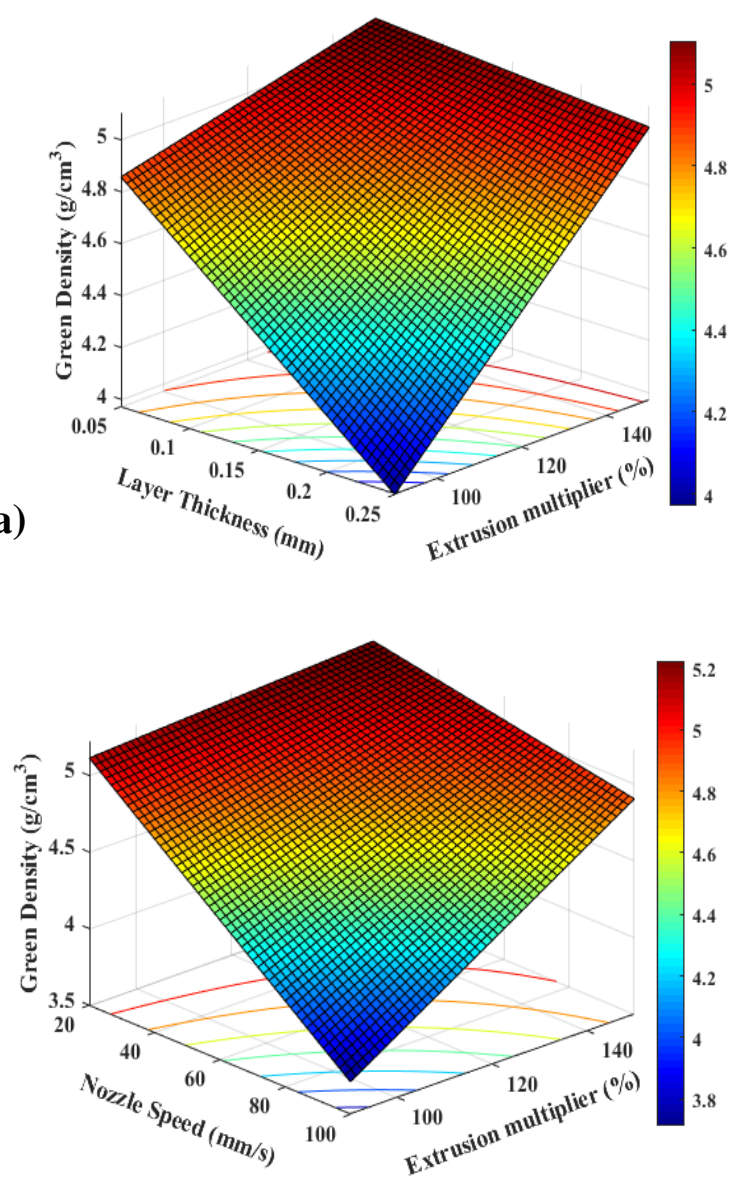
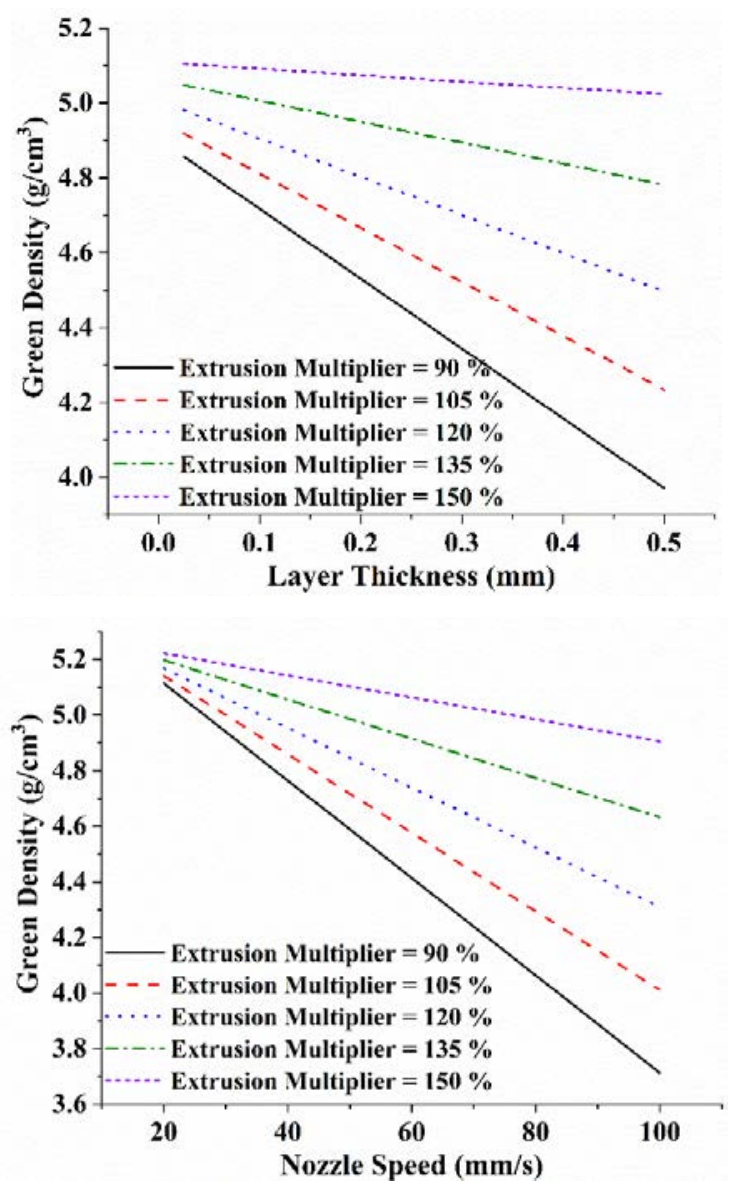


\section{(b)}

Fig. 7: 3D surface plots and 2D line plots for the interactions between (a) layer thickness and extrusion multiplier, and (b) nozzle speed and extrusion multiplier for green density.

The significant interactions for the green density obtained after the ANOVA analysis are between X1-X3 and X2-X3, i.e., layer thickness-extrusion multiplier and nozzle speed-extrusion multiplier, respectively (Eqn (3)). Figure 7 (a) depicts the 3D surface and 2D line plots for the interaction between layer thickness and the extrusion multiplier. The effect of change in extrusion multiplier is less significant in small layer thickness samples as compared to large layer thickness samples. The extrusion and printing voids are less numerous with smaller layer thickness. Therefore, the change in extrusion multiplier has less effect. The maximum value of green density is observed with low layer thickness and high extrusion multiplier combination. As the degradation of polymers is a time and temperature dependent process, an interaction effect between the extrusion temperature and the nozzle speed was expected, but such effect did not appear, likely because of the parameter ranges chosen in this study.

\subsection{Effect of parameters on surface roughness}

The individual effects of the parameters on the surface roughness are shown in Fig. 8(a). The percentage contributions of the individual terms and their interactions are also given in Fig. 8(b). The layer thickness and nozzle speed are the dominating parameters. For the set of experiments carried out, the surface roughness was in the range 7-18 $\mu \mathrm{m}$. An in-depth discussion about these effects is given in next subsections. 


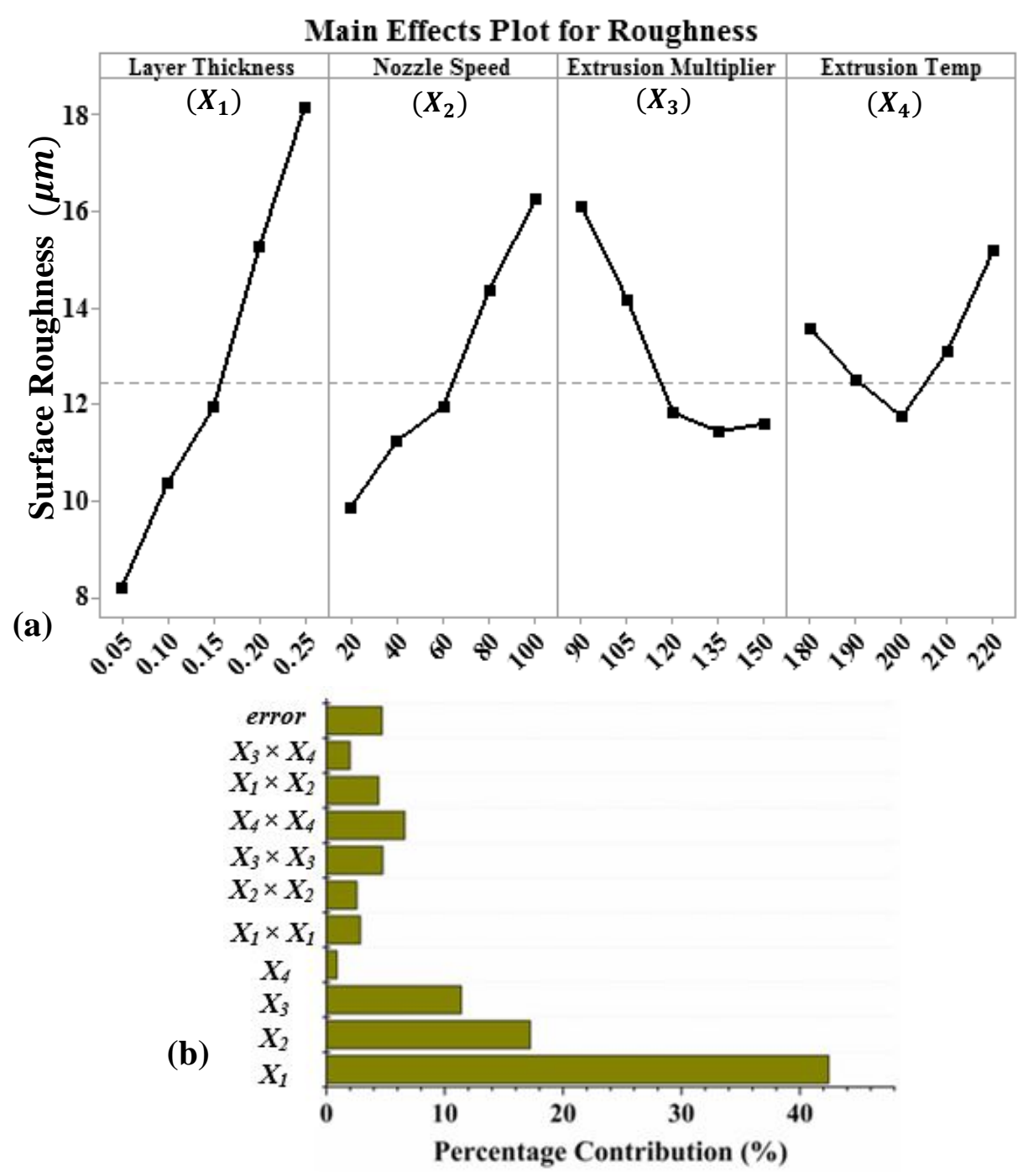

Fig. 8: (a) Parameter effect and (b) percentage contributions for surface roughness.

\subsubsection{Effect of layer thickness}

The layer thickness is the most dominating parameter affecting the surface roughness in extrusionbased 3D printing of thermoplastic material [43]. A similar result was obtained here for the extrusion printing of copper MIM feedstock. The surface roughness was observed to increase with increasing layer thickness enormously. The cusp height on the surface in the printed direction increases with increasing the layer thickness (stair-stepping effect), which induces a higher surface roughness [45]. The lower height peaks were observed on the 3D profile of the sample printed with $0.05 \mathrm{~mm}$ layer thickness (Fig. 9 (a)) as compared to the 3D profile of the sample printed with $0.25 \mathrm{~mm}$ layer thickness (Fig. 9 (b)). The line plots also show the same trend with lower peaks for 
lower layer thickness (Fig. 9 (c)). The stair-stepping effect also creates some geometrical differences between the CAD model and the fabricated samples due to layer stacking [46]. The minimum layer thickness results in the lowest surface roughness and in the most accurate dimensions. However, the fabrication time is increased. A similar relation between layer thickness and surface roughness was noticed by Zhang et al. [47] for the extrusion printing of WC-Co carbides and binder composite green samples.
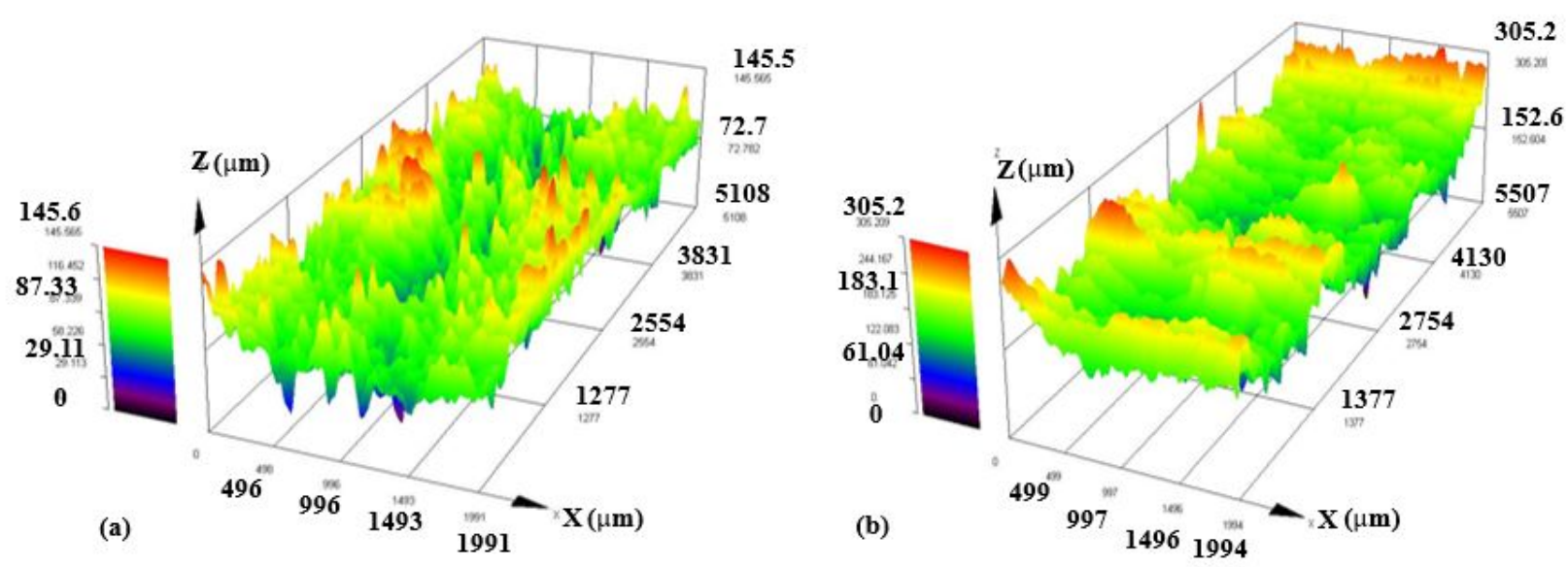

(c)

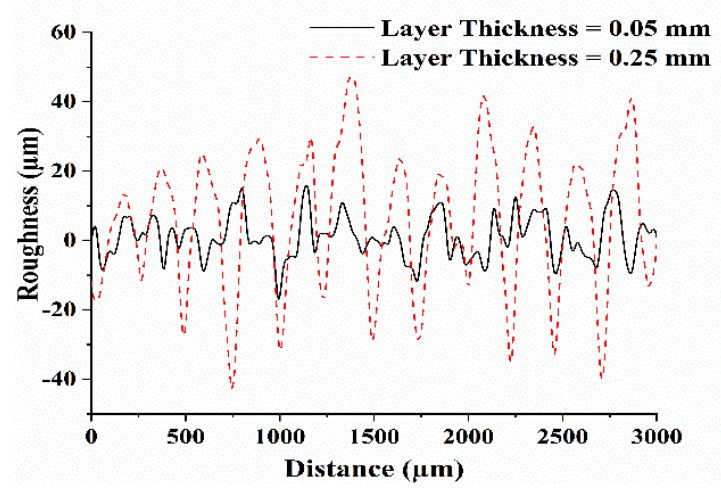

Fig. 9: Optical surface profile of the sample printed with (a) $0.05 \mathrm{~mm}$ and (b) $0.25 \mathrm{~mm}$ layer thickness, and (c) line plots for different layer thicknesses.

\subsubsection{Effect of nozzle speed}

The surface roughness was found to increase when increasing the nozzle speed. A slow nozzle speed induces a more homogeneous deposition of the extruded material, as observed above in the green density analysis, and lower surface roughness was measured. Low peaks were observed on the 3D profile of the sample printed with $20 \mathrm{~mm} / \mathrm{s}$ nozzle speed. On the contrary, a fast nozzle 
speed results in large voids, a low surface finish and then to a high roughness value. Similar observations were made for FDM printing of polylactic acid (PLA) by Radhwan et al. [48].

\subsubsection{Effect of extrusion multiplier}

The surface roughness decreases with the extrusion multiplier increasing from $90 \%$ to $120 \%$. The low extrusion multiplier value leads to an inhomogeneous deposition of the extruded material. This results in large voids on the surface, as noted above in the green density analysis. The printed surface thus exhibited a poor surface finish and a low roughness. The SEM images of the sample fabricated with $120 \%$ multiplier (Fig. 6(b)) shows a better surface with fewer voids. The surface roughness, however, begins to increase when the extrusion multiplier is increased above $135 \%$. Such a trend was not observed for the green density. This is because extra material is deposited on the surface for a too high value of the extrusion multiplier. The SEM image of the sample fabricated with $150 \%$ extrusion multiplier (Fig. 6 (g)) depicts the extra deposition of material.

\subsubsection{Effect of extrusion temperature}

The extrusion temperature does not significantly affect the surface roughness (Fig. 8 (b)). As for the green density, a non-monotonous variation was found. The surface roughness decreases with the extrusion temperature increasing from 180 to $200{ }^{\circ} \mathrm{C}$. This can be explained by the lower viscosity of the material extruded at $200^{\circ} \mathrm{C}$, resulting in fewer voids at the surface. Large voids can indeed be observed on the sample fabricated at $180^{\circ} \mathrm{C}$ (Fig. 6 (h)), having the higher surface roughness. However, the surface roughness increases with the extrusion temperature increasing from 200 to $220^{\circ} \mathrm{C}$. This can be explained by the degradation of the binder at high temperature, as already discussed in the green density analysis, leading to large extrusion voids (Fig. 6 (i)). Finally, the sample prepared at $200^{\circ} \mathrm{C}$ extrusion temperature showed the best surface finish.

\subsubsection{Effect of interactions}

Two significant interactions were obtained after the ANOVA analysis for the surface roughness. Figure 10 (a) depicts the 3D surface and 2D line plots for the interaction between nozzle speed and layer thickness. Large layer thickness values have not a significant impact on surface roughness at high nozzle speeds. Large extrusion and printing voids are created with a fast nozzle speed, whatever the layer thickness. On the other side, homogenous deposition of the material can occur at slow nozzle speed. Therefore, small layer thickness at slow nozzle speed gives the lowest value 
of surface roughness. A similar observation of the interaction between nozzle speed and layer thickness was found by Saad et al. [49] for FDM printing of PLA.

Figure 10 (b) depicts the 3D surface and 2D line plots for the interaction between extrusion temperature and the extrusion multiplier. The lowest surface roughness value was obtained for medium values of extrusion temperature and the extrusion multiplier. At low values of the extrusion multiplier, the extrusion temperature has a significant effect on the roughness, whereas at high values of extrusion multiplier it has insignificant effect from 190 to $220{ }^{\circ} \mathrm{C}$ extrusion temperature. It could be due to the high flow rate of material, which could compensate for the degradation of the binder and maintain the low surface roughness.
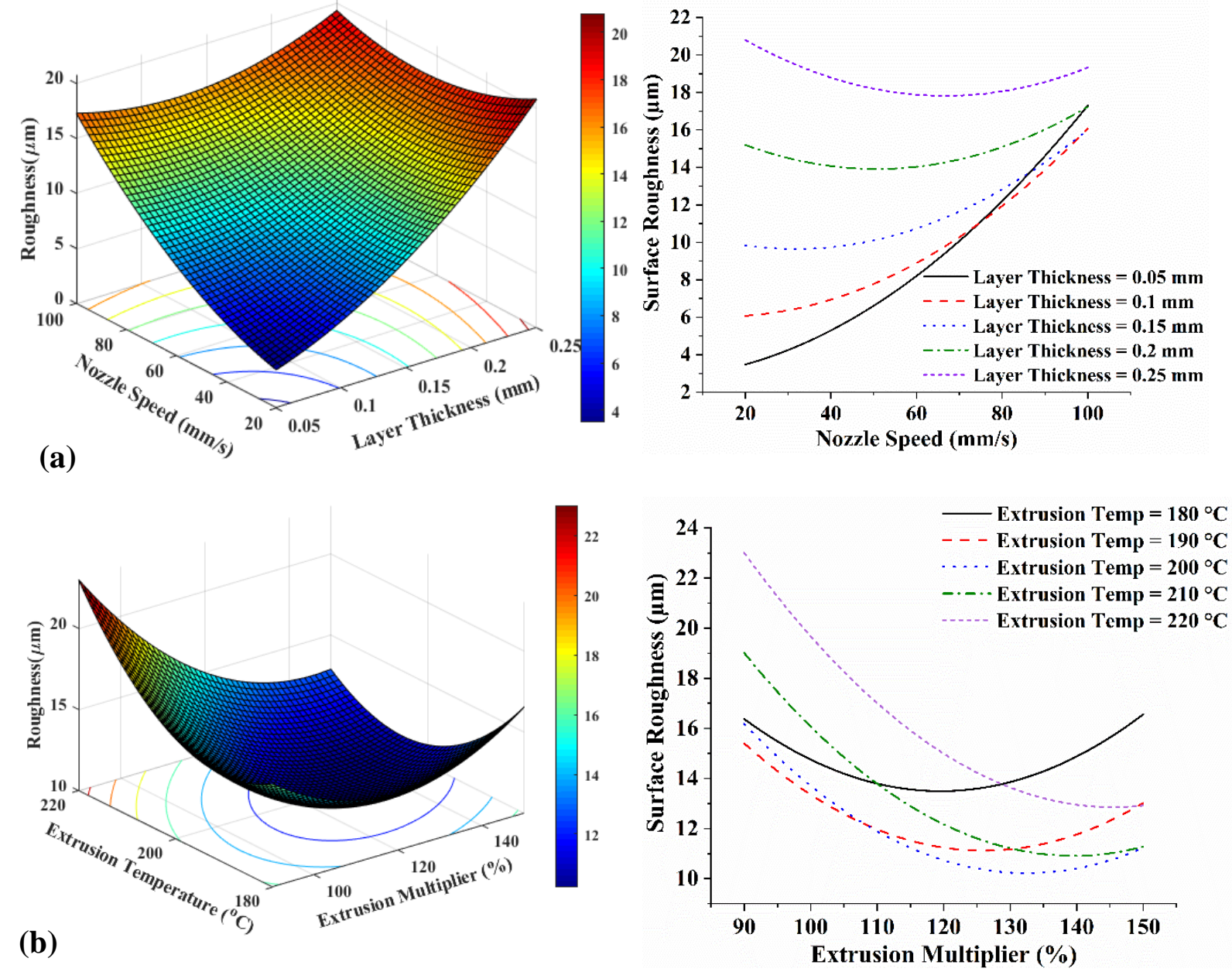

Fig. 10: 3D surface plots and 2D line plots for the interactions between (a) layer thickness and nozzle speed, and (b) extrusion temperature and extrusion multiplier for surface roughness. 


\subsection{Multi-objective optimization}

The multi-objective optimization genetic algorithm was used to maximize the green density and minimize surface roughness. The optimization toolbox from MATLAB 2015 (USA) was used for the optimization. The equations of green density and surface roughness (Eqs. 3 and 4) were used as the objective functions. The details of the constraints for the optimization are given below.

$$
\text { Minimize } f=\left(\frac{1}{G D}, S R\right)
$$

Subject to,

$$
\begin{gathered}
0.05 \leq X_{1} \leq 0.25 \\
20 \leq X_{2} \leq 100 \\
90 \leq X_{3} \leq 150 \\
180 \leq X_{4} \leq 220
\end{gathered}
$$

Table 3: Optimized results with parameters and responses values.

\begin{tabular}{|c|c|c|c|c|c|c|c|}
\hline & & & & \multicolumn{2}{|c|}{$\begin{array}{c}\text { Green Density } \\
\left(\mathbf{g} / \mathbf{c m}^{\mathbf{3}}\right)\end{array}$} & \multicolumn{2}{c|}{$\begin{array}{c}\text { Surface Roughness } \\
(\boldsymbol{\mu m})\end{array}$} \\
\hline $\boldsymbol{X}_{\mathbf{1}}$ & $\boldsymbol{X}_{\mathbf{2}}$ & $\boldsymbol{X}_{\mathbf{3}}$ & $\boldsymbol{X}_{\mathbf{4}}$ & Model & Experimental & Model & Experimental \\
\hline 0.05 & 20 & 120 & 196 & $5.42 \pm 0.11$ & 5.55 & $3.44 \pm 1.92$ & 1.59 \\
\hline
\end{tabular}

Table 3 depicts the chosen optimized parameters and the obtained responses. According to the estimate, it is feasible to achieve a sample with a green density of $5.42 \mathrm{~g} / \mathrm{cm} 3$ and a surface roughness of $3.4 \mu \mathrm{m}$ with a layer thickness of $50 \mu \mathrm{m}$, a nozzle velocity of $20 \mathrm{~mm} / \mathrm{s}$, an extrusion multiplier of $120 \%$ and an extrusion temperature of $196^{\circ} \mathrm{C}$. It should be noted that this green density value is much higher than the highest obtained during the DOE process and that the surface roughness is much lower than the lowest obtained during the DOE process. Three experiments were performed with the optimized parameters. The measured values of green density and surface roughness were in the error range of the statistical models. Figure 11 depicts the SEM image and 3D surface profile of the sample fabricated with the optimized parameters. A smooth surface with 
minor extrusion and printing voids was observed from the SEM image. Moreover, the low peaks with the surface profile depict the excellent surface finish. The interest of the DOE approach is thus clearly demonstrated.

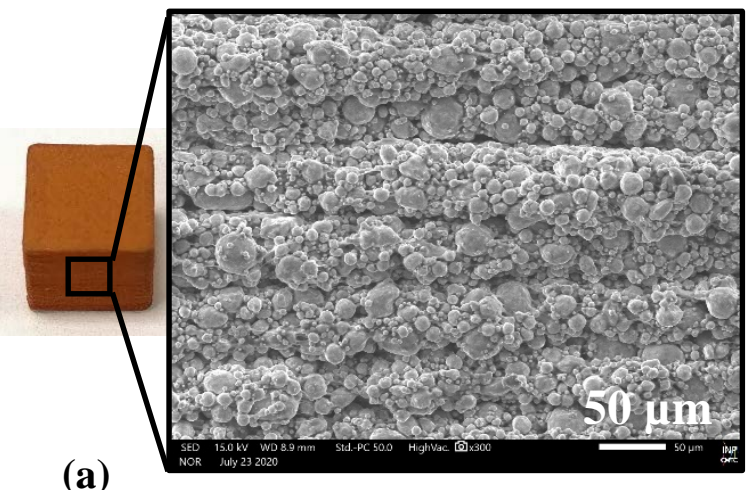

(b)

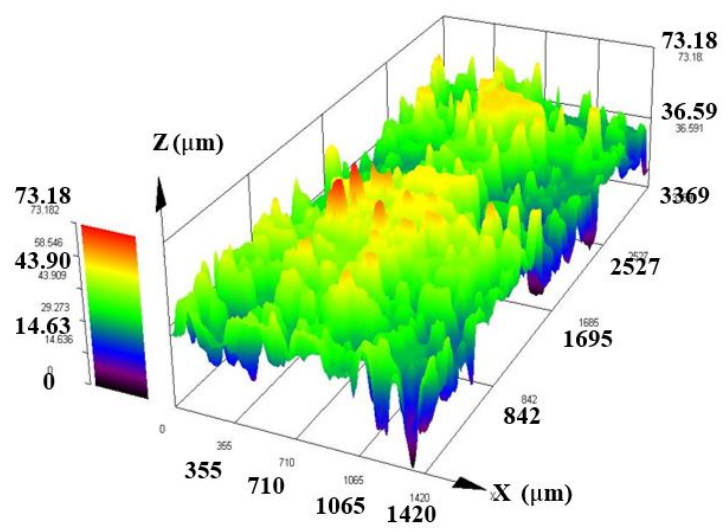

Fig. 11: (a) SEM image and (b) 3D surface profile of the sample fabricated with optimized parameters.

(a)
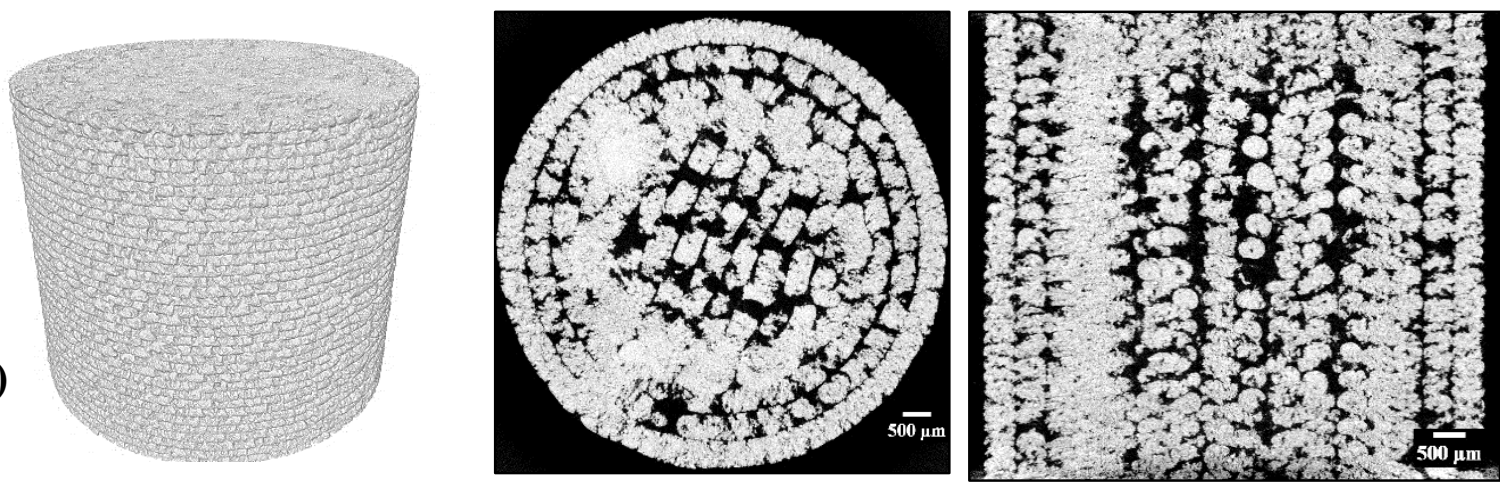

(b)
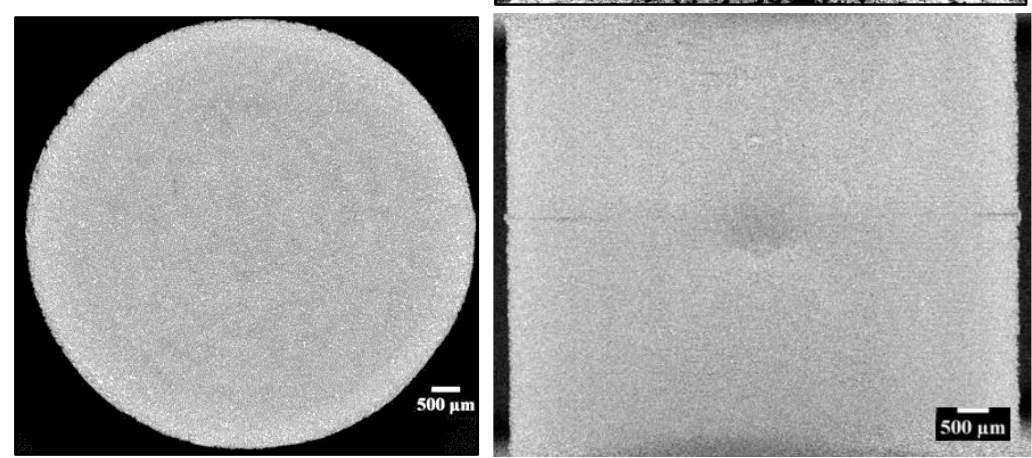
Fig. 12: Micro-tomography analysis of green sample fabricated with (a) non-optimized parameters and (b) optimized parameters. (left to right: tomography 3D image, a horizontal and vertical cross-section

A micro-tomography analysis was performed to observe the extrusion voids in the bulk of the samples and validate some of the assumptions previously made. This analysis was performed on a green sample printed with arbitrary chosen non-optimized parameters (layer Thickness: $0.2 \mathrm{~mm}$, nozzle speed: $60 \mathrm{~mm} / \mathrm{s}$, extrusion multiplier: $100 \%$, extrusion Temp: $210{ }^{\circ} \mathrm{C}$ ) and on a sample printed with previously reported optimized parameters. Figure 12 (a) and (b) depict a 3D rendering of the tomography image and horizontal and vertical virtual sections for each green sample. The poor material deposition (large extrusion and printing voids) is noticed in the non-optimized sample. It is due to the high nozzle speed, large layer thickness, low extrusion multiplier and high extrusion temperature. In terms of extrusion voids, the degradation of material during extrusion is also observed due to high extrusion temperatures. On the other side, with optimized parameters, the sample exhibits a much denser structure with few voids.

\subsection{Sintering}

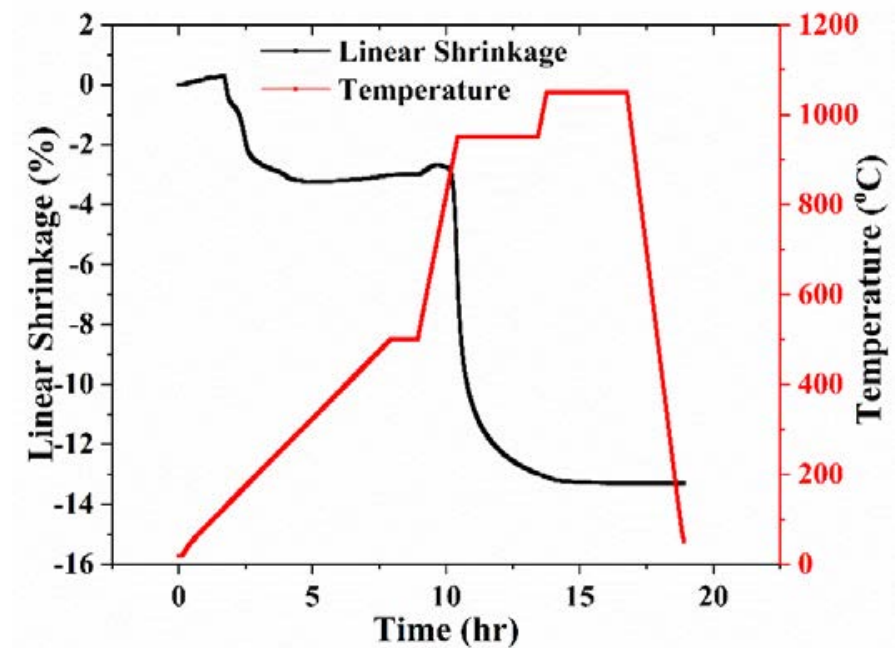

Fig. 13: Thermal profile of debinding and sintering and corresponding linear shrinkage.

The sample printed with the optimized parameters was debinded and sintered to obtain a dense copper part. The green sample was dipped in water for $14 \mathrm{~h}$ at room temperature to remove the water dissolved binder (PEG) as the solvent debinding step. A reduction of $3.2 \mathrm{wt} \%$ was observed after drying the sample in the oven. Further, the sample was placed in the dilatometer for successive thermal debinding and sintering as per the thermal cycle shown in Fig. 13. 
(a)
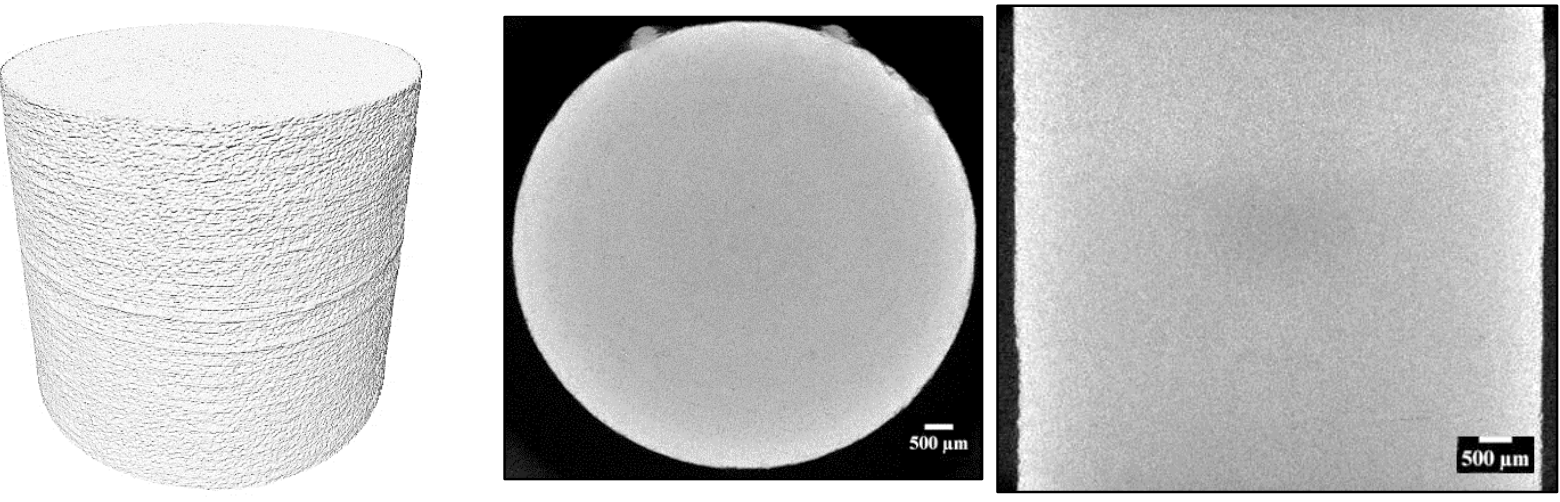

(b)
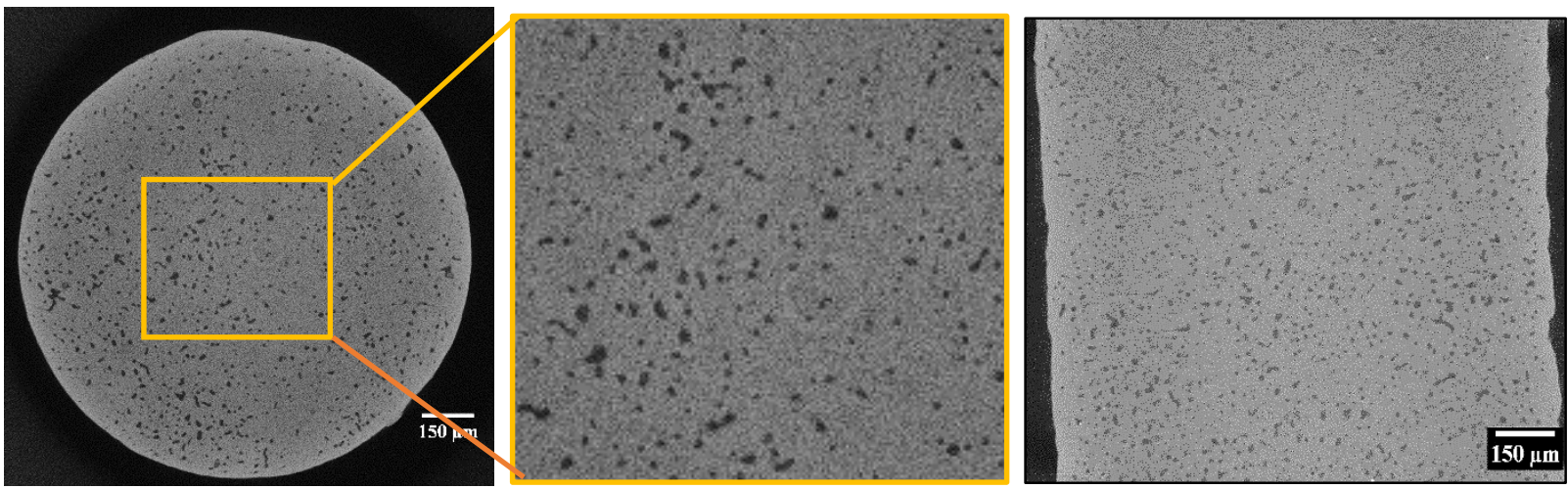

Fig. 14: Micro-tomography analysis of the sintered sample with (a) low and (b) high resolution

(sample was machined to small radius for the high-resolution scan).

The shrinkage of the sample is observed between $180^{\circ} \mathrm{C}$ and $300{ }^{\circ} \mathrm{C}$ in the thermal debinding stage. The binders are eliminated after the $500{ }^{\circ} \mathrm{C}$ holding time. Continuous sintering shrinkage is then observed above $850{ }^{\circ} \mathrm{C}$. The isotropic shrinkage of $\sim 13 \%$ and a weight density of $8.4 \mathrm{~g} / \mathrm{cm}^{3}$ were measured at the end of the sintering cycle. Dividing the latter value by the weight density of copper $\left(8.96 \mathrm{~g} / \mathrm{cm}^{3}\right)$, a relative density of $90.8 \%$ is found. The surface roughness of the sintered sample was measured as $2.42 \pm 0.92 \mu \mathrm{m}$. The total mass reduction during debinding and sintering was calculated as $6.4 \%$, which is close to TGA weight loss of the feedstock. Figure 14 (a) depicts a 3D rendering of the tomography image of the sintered sample with $\sim 6 \mu \mathrm{m}$ voxel size, as well as horizontal and vertical virtual sections. The sample does not show any large pore that could be due to printing defects. To get higher resolution image ( $\sim 0.9 \mu \mathrm{m}$ voxel size) a $1-\mathrm{mm}$ diameter cylinder was machined out of this sintered sample. Fig. 14(b)) shows small pores, mainly of the size of initial copper particles, which are due to incomplete sintering. 


\section{Conclusions}

The present work deals with the optimization of extrusion printing parameters using copper MIM (metal injection moulding) feedstock to obtain maximum green density and minimum surface roughness. The design of experiments based on central composite design (CCD) approach was used for defining the experiments and developing quadratic statistical models between four process parameters (layer thickness, nozzle speed, extrusion multiplier, and extrusion temperature) for two responses (green density and surface roughness). The sample printed with optimized parameters was characterized and finally debinded and sintered. A micro-tomography analysis allowed viewing the voids in green samples fabricated with either non-optimized or optimized parameters, and in a sintered sample. The following conclusions can be drawn:

- The green density was found to decrease with increasing layer thickness, nozzle speed and decreasing extrusion multiplier. A small layer thickness facilitates lateral spreading of the material and reduces the printing voids, and a slow nozzle speed allows a more homogenous deposition with few extrusion voids. The high extrusion multiplier increases the flow rate to reduce the extrusion and printing voids. The highest density was obtained at $190{ }^{\circ} \mathrm{C}$ extrusion temperature, which provides adequate viscosity for the extrusion and the adhesion between the layers without binder degradation. Significant interactions between extrusion multiplier and layer thickness, and nozzle speed and extrusion multiplier were also found for the green density.

- The surface roughness was found to increase with increasing layer thickness and nozzle speed. A large layer thickness induces high cusp height, and high nozzle speed leads to a lack of material deposition. The roughness was found to be stable between 105 and $150 \%$ extrusion multiplier due to the excess amount of material flow. The lowest surface roughness occurred at $200{ }^{\circ} \mathrm{C}$ extrusion temperature due to optimal material viscosity.

- The multi-objective based genetic algorithm was used to maximize the green density and to minimize the surface roughness. Experiments were performed at the optimized parameters (layer thickness $=0.05 \mathrm{~mm}$, nozzle speed $=20 \mathrm{~mm} / \mathrm{s}$, extrusion multiplier $=120$

$\%$ and extrusion temperature $=196{ }^{\circ} \mathrm{C}$ ) and resulted in $5.5 \mathrm{~g} / \mathrm{cm}^{3}$ green density and $1.6 \mu \mathrm{m}$ surface roughness. 
- An optimized sample was sintered with a two-stage sintering cycle at $950{ }^{\circ} \mathrm{C}$ for $3 \mathrm{~h}$ and $1030{ }^{\circ} \mathrm{C}$ for $3 \mathrm{~h}$ after solvent and thermal debinding. The shrinkage was observed to be isotropic with $\sim 13 \%$ value, and the sintered sample possessed $\sim 91 \%$ relative density and $2.4 \mu \mathrm{m}$ surface roughness. The micro-tomography analysis revealed numerous large voids in the $3 \mathrm{D}$ printed sample with non-optimized parameters and a few small voids in the sample printed with optimized parameters. In the optimized sintered sample, micron-size pores were observed at high-resolution tomography, due to incomplete sintering.

Hence, the optimized 3D printing extrusion process has shown remarkable ability to print a copper green part with maximum green density and minimum surface roughness. However, further optimization of the debinding and sintering cycle is required to obtain a maximum sintered density, which is the future interest of the authors. Also, the processing of more complex shape parts should be investigated. The optimized printing parameters could also be used for the 3D printing of other MIM feedstocks.

\section{Acknowledgements}

The authors thank Institute Carnot Energies du Future and Labex CEMAM for their significant contribution to the funding of this work.

\section{References}

[1] R. Jisa, S. Laumann, C. Tomastik, R. Eberle, M. Keppeler, F. Franek, S. Laumann, C. Tomastik, R. Eberle, M. Keppeler, R. Jisa, S. Laumann, C. Tomastik, R. Eberle, M. Keppeler, U. Hofmann, F. Franek, Tribological properties of MIM manufactured copper alloys Tribological properties of MIM manufactured copper alloys, Tribol. - Mater. Surfaces Interfaces. 8 (2014) 27-34. doi:10.1179/1751584X14Y.0000000064.

[2] A.S. Muhsan, F. Ahmad, N.M. Mohamed, P. Sri, M. Megat, M.R. Raza, Uniform Dispersion of Multiwalled Carbon Nanotubes in Copper Matrix Nanocomposites Using Metal Injection Molding Technique, Int. J. Manuf. Eng. 2013 (2013) 1-9.

[3] A. Bandyopadhyay, K.D. Traxel, Invited review article : Metal-additive manufacturing Modeling strategies for application-optimized designs, Addit. Manuf. 22 (2018) 758-774. doi:10.1016/j.addma.2018.06.024. 
[4] S. Singh, S. Ramakrishna, R. Singh, Material issues in additive manufacturing: A review, J. Manuf. Process. 25 (2017) 185-200. doi:10.1016/j.jmapro.2016.11.006.

[5] T. El-wardany, Y. She, V. Jagdale, J.K. Garofano, J. Liou, W. Schmidt, Challenges in 3D Prinitng of High Conductivity Copper, in: ASME 2017 Int. Tech. Conf. Exhib. Packag. Integr. Electron. Photonic Microsystems Collocated with ASME 2017 Conf. Inf. Storage Process. Syst., California, USA, 2017: pp. 1-10. doi:10.1115/IPACK2017-74306.

[6] J.P. Kruth, X. Wang, T. Laoui, L. Froyen, Lasers and materials in selective laser sintering, Assem. Autom. 23 (2003) 357-371.

[7] S.R. Pogson, P. Fox, C.J. Sutcliffe, W. O’Neill, The production of copper parts using DMLR, Rapid Prototyp. J. 9 (2003) 334-343. doi:10.1108/13552540310502239.

[8] H.H. Zhu, J.Y.H. Fuh, L. Lu, Microstructural evolution in direct laser sintering of Cubased metal powder, Rapid Prototyp. J. 11 (2005) 74-81. doi:10.1108/13552540510589430.

[9] C. Silbernagel, L. Gargalis, I. Ashcroft, R. Hague, M. Galea, P. Dickens, Electrical resistivity of pure copper processed by medium-powered laser powder bed fusion additive manufacturing for use in electromagnetic applications, Addit. Manuf. 29 (2019) 100831. doi:10.1016/j.addma.2019.100831.

[10] S.D. Jadhav, S. Dadbakhsh, L. Goossens, J.P. Kruth, J. Van Humbeeck, K. Vanmeensel, Influence of selective laser melting process parameters on texture evolution in pure copper, J. Mater. Process. Technol. 270 (2019) 47-58.

doi:10.1016/j.jmatprotec.2019.02.022.

[11] S. Scudino, C. Unterdörfer, K.G. Prashanth, H. Attar, N. Ellendt, V. Uhlenwinkel, J. Eckert, Additive manufacturing of Cu-10Sn bronze, Mater. Lett. 156 (2015) 202-204. doi:10.1016/j.matlet.2015.05.076.

[12] A. Popovich, V. Sufiiarov, I. Polozov, E. Borisov, D. Masaylo, A. Orlov, Microstructure and mechanical properties of additive manufactured copper alloy, Mater. Lett. 179 (2016) 38-41. doi:10.1016/j.matlet.2016.05.064.

[13] A.P. Ventura, C.A. Wade, G. Pawlikowski, M. Bayes, M. Watanabe, W.Z. Misiolek, 
Mechanical Properties and Microstructural Characterization of Cu-4.3 Pct Sn Fabricated by Selective Laser Melting, Metall. Mater. Trans. A Phys. Metall. Mater. Sci. 48 (2017) 178-187. doi:10.1007/s11661-016-3779-x.

[14] D.A. Ramirez, L.E. Murr, S.J. Li, Y.X. Tian, E. Martinez, J.L. Martinez, B.I. Machado, S.M. Gaytan, F. Medina, R.B. Wicker, Open-cellular copper structures fabricated by additive manufacturing using electron beam melting, Mater. Sci. Eng. A. 528 (2011) 5379-5386. doi:10.1016/j.msea.2011.03.053.

[15] M.A. Lodes, R. Guschlbauer, C. Körner, Process development for the manufacturing of 99.94\% pure copper via selective electron beam melting, Mater. Lett. 143 (2015) 298301. doi:10.1016/j.matlet.2014.12.105.

[16] S.J. Raab, R. Guschlbauer, M.A. Lodes, C. Körner, Thermal and Electrical Conductivity of 99.9\% Pure Copper Processed via Selective Electron Beam Melting, Adv. Eng. Mater. 18 (2016) 1661-1666. doi:10.1002/adem.201600078.

[17] R. Guschlbauer, S. Momeni, F. Osmanlic, C. Körner, Process development of 99.95\% pure copper processed via selective electron beam melting and its mechanical and physical properties, Mater. Charact. (2018) 0-1. doi:10.1016/j.matchar.2018.04.009.

[18] D.A. Ramirez, L.E. Murr, E. Martinez, D.H. Hernandez, J.L. Martinez, B.I. MacHado, F. Medina, P. Frigola, R.B. Wicker, Novel precipitate-microstructural architecture developed in the fabrication of solid copper components by additive manufacturing using electron beam melting, Acta Mater. 59 (2011) 4088-4099. doi:10.1016/j.actamat.2011.03.033.

[19] G. Singh, P.M. Pandey, Topological ordered copper graphene composite foam: Fabrication and compression properties study, Mater. Lett. 257 (2019) 1-5. doi:10.1016/j.matlet.2019.126712.

[20] G. Singh, S. Singh, J. Singh, P.M. Pandey, Parameters effect on electrical conductivity of copper fabricated by rapid manufacturing, Mater. Manuf. Process. 00 (2020) 1-12. doi:10.1080/10426914.2020.1784937.

[21] Y. Bai, C.B. Williams, an Exploration of Binder Jetting of Copper, Rapid Prototyp. J. 21 (2015) 177-185. doi:10.1108/RPJ-12-2014-0180. 
[22] Y. Bai, G. Wagner, C.B. Williams, Effect of Particle Size Distribution on Powder Packing and Sintering in Binder Jetting Additive Manufacturing of Metals, J. Manuf. Sci. Eng. 139 (2017) 1-6. doi:10.1115/1.4036640.

[23] G. Singh, P.M. Pandey, Ultrasonic Assisted Pressureless Sintering for rapid manufacturing of complex copper components, Mater. Lett. 236 (2019) 276-280. doi:10.1016/j.matlet.2018.10.123.

[24] G. Singh, P.M. Pandey, Rapid manufacturing of copper-graphene composites using a novel rapid tooling technique, Rapid Prototyp. J. (2020). doi:10.1108/RPJ-10-2019-0258.

[25] G. Singh, P.M. Pandey, Experimental investigations into mechanical and thermal properties of rapid manufactured copper parts, Proc. Inst. Mech. Eng. Part C J. Mech. Eng. Sci. 234 (2020) 82-95. doi:10.1177/0954406219875483.

[26] G. Singh, P.M. Pandey, Uniform and graded copper open cell ordered foams fabricated by rapid manufacturing: surface morphology, mechanical properties and energy absorption capacity, Mater. Sci. Eng. A. 761 (2019) 138035. doi:10.1016/j.msea.2019.138035.

[27] G. Singh, P.M. Pandey, Rapid manufacturing of copper components using 3D printing and ultrasonic assisted pressureless sintering: experimental investigations and process optimization, J. Manuf. Process. 43 (2019) 253-269. doi:10.1016/j.jmapro.2019.05.010.

[28] K. Rane, K. Castelli, M. Strano, Rapid surface quality assessment of green 3D printed metal-binder parts, J. Manuf. Process. 38 (2019) 290-297. doi:10.1016/j.jmapro.2019.01.032.

[29] K. Rane, S. Petrò, M. Strano, Evolution of porosity and geometrical quality through the ceramic extrusion additive manufacturing process stages, Addit. Manuf. 32 (2020) 101038. doi:10.1016/j.addma.2020.101038.

[30] D. Godec, S. Cano, C. Holzer, J. Gonzalez-Gutierrez, Optimization of the 3D printing parameters for tensile properties of specimens produced by fused filament fabrication of 17-4PH stainless steel, Materials (Basel). 13 (2020). doi:10.3390/ma13030774.

[31] J. Gonzalez-Gutierrez, F. Arbeiter, T. Schlauf, C. Kukla, C. Holzer, Tensile properties of sintered 17-4PH stainless steel fabricated by material extrusion additive manufacturing, 
Mater. Lett. 248 (2019) 165-168. doi:10.1016/j.matlet.2019.04.024.

[32] Y. Thompson, J. Gonzalez-Gutierrez, C. Kukla, P. Felfer, Fused filament fabrication, debinding and sintering as a low cost additive manufacturing method of 316L stainless steel, Addit. Manuf. 30 (2019) 100861. doi:10.1016/j.addma.2019.100861.

[33] S. Hong, C. Sanchez, H. Du, N. Kim, Fabrication of 3D Printed Metal Structures by Use of High-Viscosity Cu Paste and a Screw Extruder, J. Electron. Mater. 44 (2015) 836-841. doi:10.1007/s11664-014-3601-8.

[34] X. Yan, L. Hao, W. Xiong, D. Tang, Research on influencing factors and its optimization of metal powder injection molding without mold via an innovative 3D printing method, RSC Adv. 7 (2017) 55232-55239. doi:10.1039/c7ra11271h.

[35] Y. Zhao, W. Gao, J. Xi, H. Li, F. Ren, Development of copper powder paste for direct printing and soft mold casting, Addit. Manuf. 31 (2020) 100992. doi:10.1016/j.addma.2019.100992.

[36] L. Ren, X. Zhou, Z. Song, C. Zhao, Q. Liu, J. Xue, X. Li, Process parameter optimization of extrusion-based 3D metal printing utilizing PW-LDPE-SA binder system, Materials (Basel). 10 (2017). doi:10.3390/ma10030305.

[37] W. Lengauer, I. Duretek, M. Fürst, V. Schwarz, J. Gonzalez-Gutierrez, S. Schuschnigg, C. Kukla, M. Kitzmantel, E. Neubauer, C. Lieberwirth, V. Morrison, Fabrication and properties of extrusion-based 3D-printed hardmetal and cermet components, Int. J. Refract. Met. Hard Mater. 82 (2019) 141-149. doi:10.1016/j.ijrmhm.2019.04.011.

[38] J. Ott, A. Burghardt, D. Britz, F. Mucklich, Free-Sintering Study of Pressure-Less Manufactured Green Bodies Made of Fine Cu Powder for Electronic Applications, in: Euro PM2019 Int. Powder Metall. Congr. Exhib., Netherlands, 2019.

[39] M.K. Gupta, P.K. Sood, V.S. Sharma, Machining Parameters Optimization of Titanium Alloy using Response Surface Methodology and Particle Swarm Optimization under Minimum-Quantity Lubrication Environment, Mater. Manuf. Process. 31 (2016) 16711682. doi:10.1080/10426914.2015.1117632.

[40] V. Sharma, P.M. Pandey, Optimization of machining and vibration parameters for residual 
stresses minimization in ultrasonic assisted turning of 4340 hardened steel, Ultrasonics. 70 (2016) 172-182. doi:10.1016/j.ultras.2016.05.001.

[41] D.K. Mishra, P.M. Pandey, Experimental investigation into the fabrication of green body developed by micro-extrusion-based 3D printing process, Polym. Compos. (2020) 1-18. doi:10.1002/pc.25514.

[42] M. Galati, P. Minetola, Analysis of density, roughness, and accuracy of the atomic diffusion additive manufacturing (ADAM) process for metal parts, Materials (Basel). 12 (2019). doi:10.3390/ma1224122.

[43] S. Singh, G. Singh, C. Prakash, S. Ramakrishna, Current status and future directions of fused fi lament fabrication, J. Manuf. Process. 55 (2020) 288-306. doi:10.1016/j.jmapro.2020.04.049.

[44] S. Hwang, E.I. Reyes, K. sik Moon, R.C. Rumpf, N.S. Kim, Thermo-mechanical Characterization of Metal/Polymer Composite Filaments and Printing Parameter Study for Fused Deposition Modeling in the 3D Printing Process, J. Electron. Mater. 44 (2015) 771777. doi:10.1007/s11664-014-3425-6.

[45] K. Thrimurthulu, P.M. Pandey, N.V. Reddy, Optimum part deposition orientation in fused deposition modeling, Int. J. Mach. Tools Manuf. 44 (2004) 585-594. doi:10.1016/j.ijmachtools.2003.12.004.

[46] N. Ayrilmis, Effect of layer thickness on surface properties of 3D printed materials produced from wood flour/PLA filament, Polym. Test. 71 (2018) 163-166. doi:10.1016/j.polymertesting.2018.09.009.

[47] X. Zhang, Z. Guo, C. Chen, W. Yang, Additive manufacturing of WC-20Co components by 3D gel-printing, Int. J. Refract. Met. Hard Mater. 70 (2018) 215-223. doi:10.1016/j.ijrmhm.2017.10.005.

[48] H. Radhwan, Z. Shayfull, M.R. Farizuan, M.S.M. Effendi, A.R. Irfan, Optimization parameter effects on the quality surface finish of the three-dimensional printing (3Dprinting) fused deposition modeling (FDM) using RSM, AIP Conf. Proc. 2129 (2019). doi:10.1063/1.5118163. 
[49] M.S. Saad, A.M. Nor, M.E. Baharudin, M.Z. Zakaria, A.F. Aiman, Optimization of surface roughness in FDM 3D printer using response surface methodology, particle swarm optimization, and symbiotic organism search algorithms, Int. J. Adv. Manuf. Technol. 105 (2019) 5121-5137. doi:10.1007/s00170-019-04568-3.

Supplemental Material

Table S1: ANOVA analysis for green density.

\begin{tabular}{|c|c|c|c|c|c|c|c|c|}
\hline Model & DF & Seq. SS & MS & $\mathbf{F}$ & $\mathbf{P}$ & $R^{2}(\%)$ & $\begin{array}{c}\text { Adj. } R^{2} \\
(\%)\end{array}$ & Remarks \\
\hline Regression & 7 & 2.5794 & 0.36849 & 153.38 & 0 & 97.26 & 95.52 & $\begin{array}{l}F^{\text {standard1 }}(0.05,7,23)= \\
2.44\end{array}$ \\
\hline Linear & 4 & 2.267 & & & & & & \multirow{7}{*}{$\begin{array}{l}\text { Fregression }>F_{\text {standard1 }} \\
F^{\text {standard2 }}(0.05,17,23) \\
=2.09 \\
\text { Flack of fit }<F_{\text {standard2 }} \\
\text { Lack of fit is } \\
\text { irrelevant, and model } \\
\text { is acceptable }\end{array}$} \\
\hline Square & 1 & 0.19778 & & & & & & \\
\hline Interaction & 2 & 0.11371 & & & & & & \\
\hline $\begin{array}{l}\text { Residual } \\
\text { error }\end{array}$ & 23 & 0.05526 & 0.00240 & & & & & \\
\hline Lack of fit & 17 & 0.04585 & & 1.72 & 0.26 & & & \\
\hline Pure error & 6 & 0.00941 & & & & & & \\
\hline Total & 30 & 2.63466 & & & & & & \\
\hline
\end{tabular}


Table S2: ANOVA analysis for surface roughness.

\begin{tabular}{|c|c|c|c|c|c|c|c|c|}
\hline Model & DF & Seq. SS & MS & $\mathbf{F}$ & $\mathbf{P}$ & $R^{2}(\%)$ & $\begin{array}{c}\text { Adj. } \\
\text { R }^{2}(\%)\end{array}$ & Remarks \\
\hline Regression & 10 & 302.661 & 30.266 & 38.81 & 0 & 95.1 & 92.65 & $F^{\text {standard1 }}(0.05,10$, \\
\hline Linear & 4 & 238.380 & & & & & & $(20)$ \\
\hline Square & 4 & 43.04 & & & & & & Fregression $>F_{\text {standard1 }}$ \\
\hline Interaction & 2 & 21.241 & & & & & & $\begin{array}{l}20)=2.22 \\
20,14,\end{array}$ \\
\hline Residual error & 20 & 15.596 & 0.67 & & & & & $F_{\text {lack of fit }}<\mathrm{F}_{\text {standard2 }}$ \\
\hline Lack of fit & 14 & 13.233 & & 2.04 & 0.144 & & & Lack of fit is \\
\hline Pure error & 6 & 2.362 & & & & & & $\begin{array}{l}\text { irrelevant, and model } \\
\text { is acceptable }\end{array}$ \\
\hline Total & 30 & 318.257 & & & & & & \\
\hline
\end{tabular}

